\title{
BIOLOGY AND SOCIAL
}

PROBLEMS

GEORge HowARD PARKER

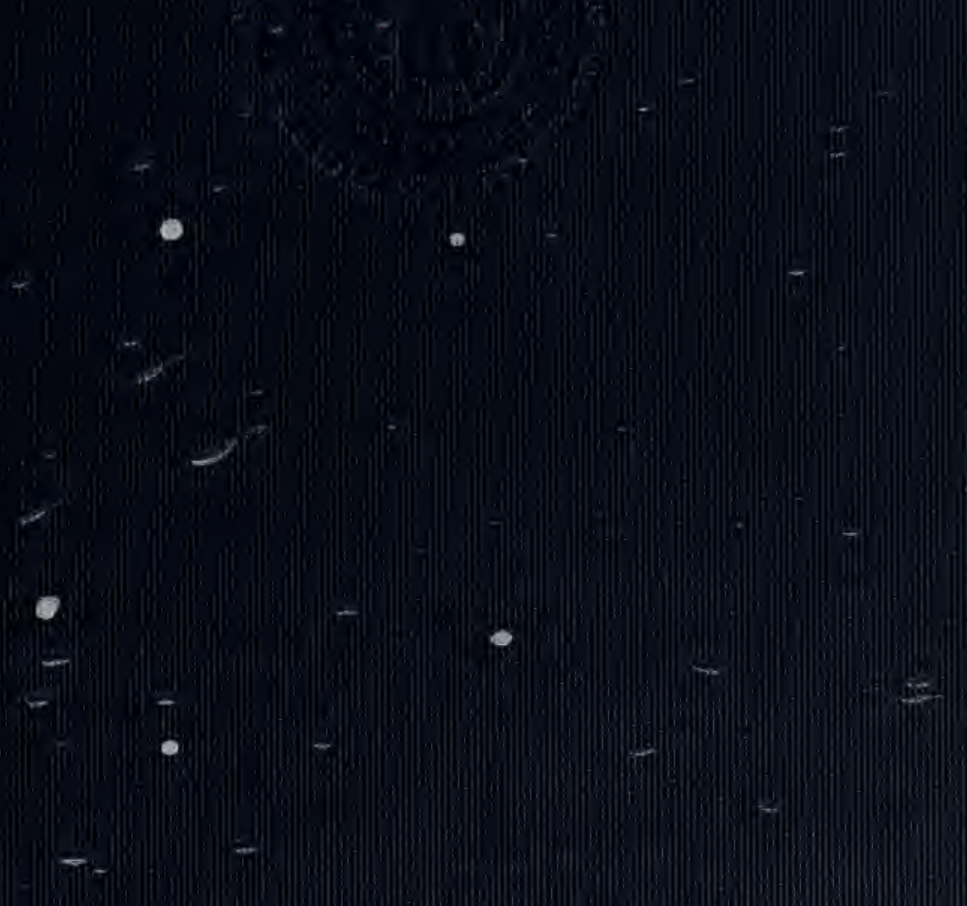





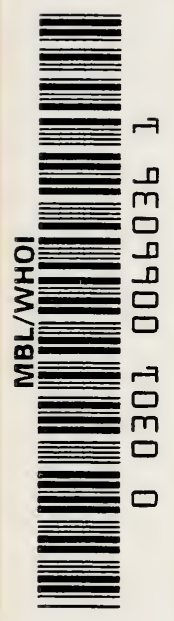






\section{The William $\not B$ remster Clark fttemorial Lectures}

THE RELIGIOUS REVOLUTION OF TO-DAY. By James T. SHOTWBLl. 1913.

BIOLOGY AND SOCIAL PROBLEMS. By GEORGE HOWARD PARKBR. 19I4.

HOUGHTON MIFFLIN COMPANY BOSTON AND NEW YORK 
The 2 illiam $\mathfrak{D r e l w a t e r}$ Clark Memarial II

1914 




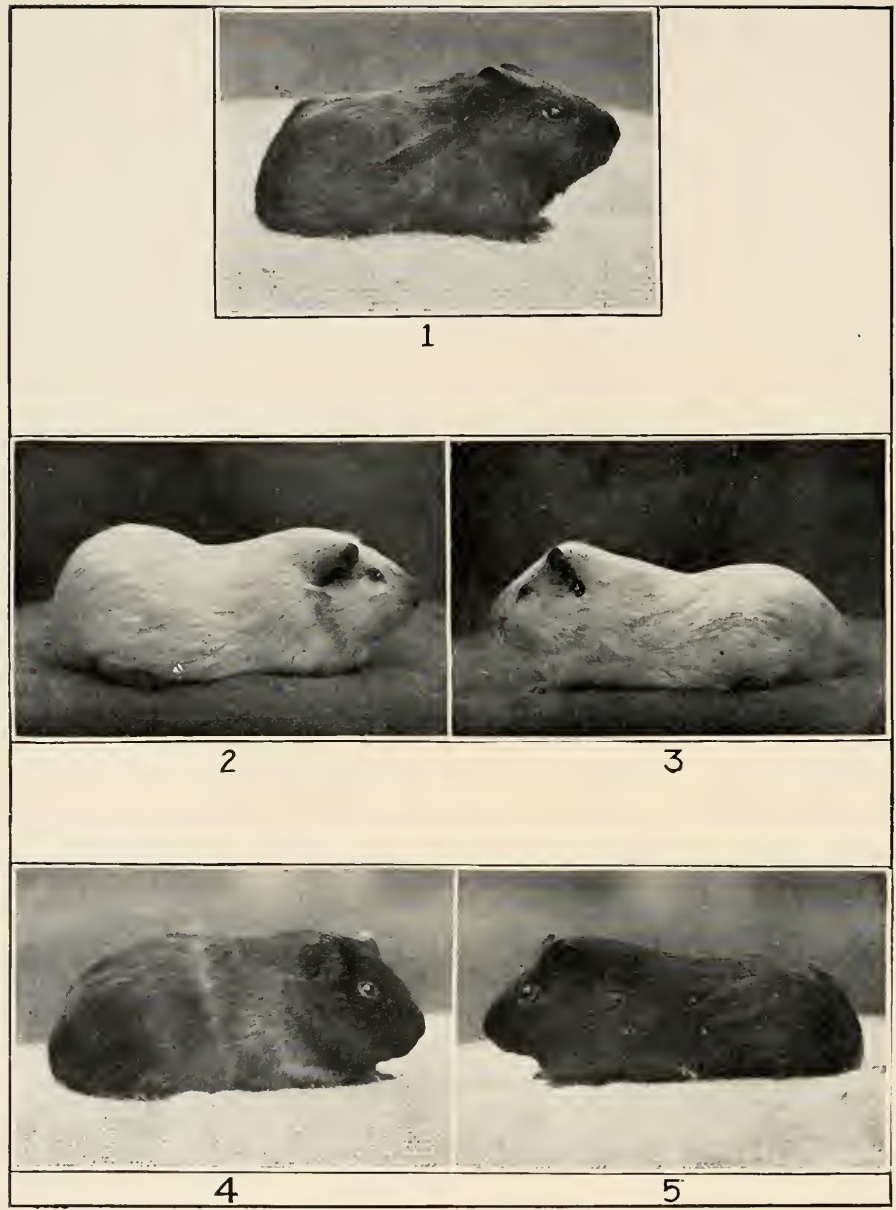

All figures after Castle

PLATE IV. OVARIAN TRANSPLANTATION

Fig. 1. A young, black guinea-pig like the one whose ovaries were transplanted into the albino shown in Fig. 2. Fig. 2. An albino gninea-pig whose ovaries were replaced by those from such a guinea-pig as that shown in Fig. 1. Fig. 3. An albino male guinea-pig with which the one shown in Fig. 2 was mated. Figs. 4 and 5. Two of the six offspring of the matings of the guinea-pigs shown in Figs. 2 and 3. All the off spring were black. 


\section{The Zilliam $\mathfrak{D r e l u g i t e r}$ Clark $\mathfrak{A}$ Qemarial Ilectureg \\ 1914}

\section{BIOLOGY AND SOCIAL \\ PROBLEMS}

BY

\section{GEORGE HOWARD PARKER, S.D}

PROFESSOR OF ZOÖLOGY IN HARVARD UNIVERSITY

AND WILLIAM BREWSTER CLARK LECTURER

AT AMHERST COLLEGE FOR 1914

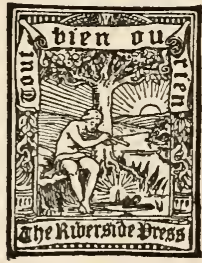

BOSTON AND NEW YORK HOUGHTON MIFFLIN COMPANY

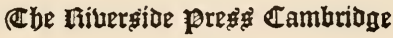


COPYRIGHT, 1914, BY GEORGE HOWARD PARKER

ALL RIGHTS RESERVED

Published November 1914 
L. M. P. 



\section{FOREWORD}

THE unique characteristic of modern times - one which gives every indication of being permanent - is that the world, both personal and external, is to an apparently increasing degree in a state of change. The immense significance of this fact is as yet but dimly perceived. The new modifies the old or displaces it in every department of life without exception and with increasing rapidity. New ideas, new movements, new ways of looking at things present themselves for attention for the first time or call upon people to change their attitude towards things they had considered settled. This state of the world renders the practical problems of personal conduct and social policy increasingly vital and complex, and makes the task of a college in its relation to them as much more difficult as an institution is less mobile than an individual.

To assist Amherst College, therefore, in throwing light in a genuinely scientific spirit upon the relation of the research, discovery, 
and thought of the day to individual attitude and social policy is our aim in the foundation of these lectures. Such light may come through a recent discovery in natural or applied science, through a new tendency in art, literature, or music; it may be the result of some painstaking research in history or anthropology; or it may be found in some vital movement, religious, philosophic, economic, or political. It is our wish that men and women who are in the position of leaders in such phases of the life of the day shall give to Amherst College and the world an exposition of their particular work in its relation to what they conceive to be a modern outlook.

We give these lectures in memory of William Brewster Clark, M.D., who graduated from Amherst in the class of 1876 . We believe that no place for a memorial to him could be more fitting than the college which he loved with a devotion characteristically rich and sincere, nor any form more suitable than lectures on subjects which to him would be most absorbing.

\section{Fanny H. Clark, W. Evans Clark.}

New York City, 11 March, 1913. 


\section{POSTSCRIPT}

Since the publication of the first series of lectures it has seemed advisable to limit the scope of future series more definitely. Should the field of subjects include all of those which affect "individual attitude and social policy," it would make for a loss of coherence and continuity in the lectures as a whole. Accordingly, we have decided to confine the subjects, for the present at least, to those which bear directly upon a most important phase of the general problem of "social policy" - that of Social Control.

The idea of unlimited human progress is but four centuries old. The idea of the conscious direction of that progress is yet in its infancy. Few indeed there are who do not still consider human characteristics, institutions, and environment to be as immutably fixed as the hills and the ocean. The merest scattering of human beings realizes that with knowledge and coöperative effort large masses of people can, in great measure, seize their destiny and mold it to their conscious aims.

With the birth of this idea of Social Control among the few have come large plans of 
social reorganization and improvement to affect the many. The salient feature of most of these plans, however, is their speculative and dogmatic quality. They lack, quite naturally, the basis of positive knowledge and experience. Social Control to-day is more prophecy than science.

It is our hope, therefore, that in these lectures we may contribute toward this new science by providing a forum for those who have data relating to the problem.

With this limitation of their scope the lectures will be continued along the lines originally planned.

F. H. C.

W. E. C.

ArdNamurchan

Lower ArgyLE, N.S.

12 August, 1914. 


\section{CONTENTS}

INTRODUCTION • • • • • • • • •

I. The Nertous System . • . . . 1

II. Hormones • • • • • • • • • 39

III. RePROdUCtION • • • • • • • 63

IV. Evolution • • • • • • • • 98 



\section{ILLUSTRATIONS}

Ovarian Transplantation (Plate IV)

(p. 111) . . . . . . . Frontispiece

From photographs in the possession of Professor W. E. Castle.

Feminized Guinea-Pigs (Plate I) • . . 52

By courtesy of Professor E. Steinach.

Mendelian Inheritance (Plate II) . . 86

From photographs in the possession of Professor W. E. Castle.

Unit Characters (Plate III) . . . • . 92

From photographs in the possession of Professor W. E. Castle. 



\section{INTRODUCTION}

Is our endeavor to better the conditions of man, probably no facts are more worthy of consideration than those included in his natural history, a science which in its wider aspects has done more in the last few centuries than any other body of knowledge to change our opinion of man's real nature and of his place in the world. How great this change has been will be evident if we compare the ancient view of man's relation to the universe with the opinions of to-day. In early times the heavens were supposed to be a dome from which showers descended upon the expanse of earth beneath, fertilizing it and rendering it a fit abode for man. Here he built habitations, cultivated the soil, and peopled the earth with his offspring. To him the earth seemed the center of the universe, and he believed that its creation was for his convenience and welfare.

But this anthropocentric conception was not without its difficulties. Even as early as the days of Aristotle, good reasons were given for the belief that the earth was not a plain 
under the vaulted heavens, but a globe. This conclusion was accepted by many of the early astronomers, and much speculation was provoked by it as to the condition of the antipodes and the relation of the earth to the heavenly bodies. In the system devised by Ptolemy in the early part of our era, the earth was placed at the center of things and the heavenly bodies were supposed to move around it. This geocentric theory was for a long time the prevailing opinion of the structure of the universe. It permeated much of the Middle Ages and afforded the physical setting for such great works of art as the Divine Comedy. It was, however, eventually replaced by the Copernican theory, according to which the sun, not the earth, is the central body around which the others move. So completely does this heliocentric theory meet the facts of astronomy that its truth is beyond dispute. But in abandoning the old for the new, man was obliged to give up his idea of a centrally located habitation. In fact it may be said that the Copernican theory removed the last physical vestige of the support for the anthropocentric conception and left this idea to survive merely as a poetic figure. 
But modern astronomy has done vastly more than displace the habitation of man from an assumed central position. It has given us a view of the structure of the universe such as was never dreamed of before. Not only is the earth one of the smaller members of an association of heavenly bodies traveling at enormous speed around a centrally located sun, but the whole solar system thus constituted, though its diameter is between five and six thousand millions of miles, is small compared with even the measurable space beyond it. The star nearest to us is alpha centauri, distant between four and five thousand times the diameter of our system. Light from this star takes over four years to reach us. No means are known for measuring the distances of the most remote stars. Some of them have been estimated to be from seven to eight thousand light-years from us; that many of them are removed by more than one hundred lightyears is certain. This distance amounts to over one hundred thousand times the diameter of our solar system and is unquestionably far short of the actual distances of many stars. None of us in this audience will live to see the light which at this moment is starting toward 
the earth from many of these bodies. Such expanses of space as are implied in these measurements were probably never imagined by even the astronomers of olden times and certainly never by those who held the ancient opinion of a flat earth vaulted by the heavens. The immensity of these stretches in relation to the earth and to man brings us to a realization of our own insignificance. Man is as the merest atom among these magnitudes; and the nations "are counted as the small dust of the balance."

If, then, the human race can no longer claim the central place in the universe, is not the observed of all observers, what can be said of it? To this question natural science has replied that man is the product of his immediate environment. And it therefore behooves those who have his welfare at heart to acquaint themselves with this environment as well as with man regarded as one of its products. It is the object of these lectures to attempt to sketch in outline something of man's nature from this standpoint.

Viewed near at hand and as a part of his immediate surroundings, man has a twofold interest. He is, first of all, an incessantly re- 
sponsive organism performing an enormous variety of complicated and intricate acts some of which are indicative of the highest order of intelligence; and, secondly, he possesses powers of reproduction in that he can leave behind him offspring who, while they carry with them the vast inheritance of the race, are also the means of that gradual change which has made his own coming possible. In dealing with the natural history of man in the following lectures these two aspects of his nature will be the chief topics for consider. ation. 



\section{BIOLOGY AND SOCIAL PROBLEMS}

\section{I \\ THE NERVOUS SYSTEM}

OF the sixteen hundred millions of human beings that populate the earth to-day experience has shown us that we usually have no difficulty in learning to distinguish one from another with perfect certainty. Physical traits, such as stature, color of hair or eyes, facial form and proportions, are the elements usually employed in this discrimination; but only a finger print may suffice. When, however, we ask ourselves what constitutes the real individual whom we have learned to know, we are less inclined to dwell on physical traits than on the innumerable characteristic movements in the form of common acts, responses, and replies which are habitual with him and which we believe to indicate in him certain mental states and attitudes that we have come to associate with him as part of his nature. 
These traits seem to us to indicate the real individual more truly than such obvious physical peculiarities as stature, color of hair, and the like, for the reason probably that experience has taught us that, though the physical traits may change with time, the others remain relatively stable and may be counted upon as more or less permanently present. We group these relatively stable traits under the head of personality, and we think of these collectively as constituting the core and essence of the individual, the real and effective part under cover of the more obviously physical, the ego or soul of the situation. It is the possession of a centralized nature, of an active personality, that makes each normal human being an effective and responsible unit in society. His attitudes are the result of this possession; his acts are determined by it; it is in fact his inmost self.

What can be said about personality so far as its natural history is concerned? How is it, for instance, related to the body? Many of the ancients believed personality to permeate more or less completely the whole human frame; it was a shade or shadow that simulated the form of the material body in all its details, but was 
airy in its lightness and transparency, and, like a shadow, it might separate itself somewhat from the body. More accustomed to think of an animal as a whole than as an assemblage of parts, they were prone to conceive of functions as more or less diffusely related to the body. Yet that a certain degree of localization was admitted is seen in the opinion ascribed to Galen that the brain is the seat of the rational soul, the heart the location of courage and fear, and the liver that of love. This localization became more or less restricted in later times. Thus, Vesalius taught, in the sixteenth century, that the chief soul was engendered in the brain by virtue of the powers of the proper material and form of that organ. And, although Stahl attempted, a century and a half later, to revive the belief that the soul and the sensorium commune were diffused over the whole body, that is, were resident as well in the tip of the finger as in the brain, the idea of the localization of these active properties in the nervous system became so well grounded through the investigations of the physicians of that time, particularly Haller, as to assume the form of permanency. This growth of knowledge led directly to the modern view that 
personality is, strictly speaking, a property of the nervous system and is in no true sense the direct result of any other system of organs. The nervous system, to be sure, is embedded among other organs of the body, and the environment thus provided influences profoundly its condition and action; but what is meant by individual personality, acuteness or dullness of sense, quickness or slowness of action, temperamental traits, such as a gloomy or bright disposition, incapacity, shiftlessness, honesty, thriftiness, or sweetness, are all, strictly speaking, functions of the nervous system. All these traits, then, that count for so much in making the individual an effective or ineffective member of society, are the direct product of his nervous system, a system which is equaled in its importance in social problems only by the reproductive system.

How the nervous system subserves personality, and how in man it has come to be the seat of that general function, are questions whose solutions are to be sought in the conditions of our nervous organs to-day and in the course which their evolution has taken.

The body of man, like that of other higher animals, is composed of an immense aggre- 
gation of cells, such as skin cells, bone cells, muscle cells, gland cells, and so forth, arranged so as to constitute its organs. The nervous system in the higher animals, like their other sets of organs, is also composed of cells, but nerve cells are very unlike other cells. Although the analysis of the body from this standpoint was undertaken three quarters of a century ago, the unique character of the nerve cell was only first fully grasped by Waldeyer in 1891. Each nerve cell, or neurone, as Waldeyer designated it, consists of a nucleated cell body, the so-called ganglion cell of the older neurologists, from which extremely attenuated processes, the nerve fibers, reach out to the most distant parts of the animal. These processes, which for a long time were not recognized as belonging to the nerve cell, are the most characteristic parts of its structure. Extending as they do in the larger animals for even some meters from their cell bodies, they afford an example of the special extension of a single cell such as is seen in no other histological element. In man, for instance, neurone processes are known to begin in the middle of the back and extend to the toes, a distance well over a meter. Although the human body con- 
tains other elongated organs than nerves, as, for example, muscles and, particularly, blood vessels, the cells of these parts are in no wise elongated as the cells of the nervous system are. In this respect the nervous system seems to be unique.

Described from the standpoint of the histological elements composing it, the nervous system of man and the other higher animals may be said to be made up of an enormously intricate system of interwoven neurones. The number of these elements in such a nervous system is incredibly great and certainly reaches many, many millions. The complexity of their arrangement is familiar to every reader of textbooks on neurology, but even the most involved descriptions in the texts are as simplicity itself compared with the real complexity in such a nervous system as that of any of the higher animals, not to mention man.

Yet, notwithstanding the enormous complexity in the arrangement of the neurones in such animals, these elements are capable of a relatively simple classification. A large number of them extend from the skin and the organs of special sense, such as the nose, the tongue, the ear, and the like, to the central 
nervous organs. These neurones become active when their sense organs are appropriately stimulated and transmit impulses from the periphery to the central organs. They are, therefore, classed as afferent or sensory neurones. Another set of neurones transmit impulses from the central organs to the muscles and other mechanisms of response. These are called efferent neurones. It might seem that the afferent neurones leading into the central organs and the efferent neurones leading out from them were all that were necessary for even a complex nervous system, but as a matter of fact there is a host of other neurones which never reach beyond the limits of the central nervous system and which are concerned with bringing one part of this system into communication with another. As a rule these neurones cannot be designated appropriately as either afferent or efferent. They have, therefore, been termed internuncial. In the higher animals they certainly far outnumber the afferent and the efferent elements collectively and constitute the bulk of the central nervous system in these forms. Thus, notwithstanding the enormous numbers of neurones in the higher animals and the intricacy 
and complexity of their arrangement, they can be grouped conveniently under the three classes, afferent, efferent, and internuncial.

The general arrangement of the neurones in any complex nervous system, as indicated in the preceding classification, foreshadows in a way the simplest complete nervous act, the reflex. When an animal is stimulated, it usually responds almost immediately by a movement. In most animals this operation is carried out by the nervous system and the appended motor organs, the muscles. Such a simple neuromuscular operation is called a reflex. It involves the stimulation and activity of an afferent neurone, whereby a nervous impulse is sent into the central organ from which issues over an efferent neurone a motor impulse that brings a muscle or a group of muscles into play. Such an action can be conceived to be restricted to the two classes of neurones mentioned, namely, the afferent and the efferent, but probably in the great majority of actual occurrences internuncial neurones are included, and these strictly central elements mediate between the central ends of the efferent and of the afferent neurones. The reflex is thus a physiological unit, so to speak, in the action 
of the nervous system, and though it can scarcely be said to exist in the bald way in which it has just been described, the idea of the reflex has been certainly a most important conception in the analysis of nervous operations.

Many of the elemental movements which the body of man is continually exhibiting partake of the nature of reflexes, and if we extend this term to include operations which involve consciousness, and there seems to be no good reason why we should not so extend it, almost every form of nervous activity may be classed under it. Many of our daily acts are reflexes of the simplest possible kind; our instinctive movements and our habits are groups of these reflexes more or less complex in their associations and in their sequences. In fact the ensemble of nervous activity that we recognize in personality rests on a background of reflex operation and is itself made up in large part of just this mode of action. Let us turn now to a consideration of some of the chief classes of nervous activity in man, that we may see something of their significance to him as a social organism.

If at the outset we attempt to discover 
those reflex operations of our bodies which seem to us to exhibit the most primitive forms of activity, we may well turn to the responses of our internal organs. The heart of a normal adult man in repose beats at a rate of about seventy pulses per minute. If he rises and stands, it usually increases its beats to about eighty per minute; if he lies down, the rate may fall to some sixty per minute. Unusual exercise, as in running and other forms of vigorous muscular work, calls forth a marked increase in the rate which may last for some time after the exercise has ceased. All these changes in the action of the heart are concerned with the appropriate supply of blood to the working body, particularly its muscles, and are of an obviously adaptive kind. Since they follow with great precision and regularity the changes in the state of the individual, they might be looked upon as good examples of simple reflexes. But a careful inspection of them will show that this is not strictly true.

The heart of man, like that of other higher animals, receives at least two kinds of nerve fibers, sympathetic and vagus fibers. The first of these on stimulation accelerates the 
heart-beat; the second retards it and may even bring it to a complete standstill. Such a control of a muscle is by no means usual and suggests at once that the heart must be an exceptional organ. But what is of still more significance than this peculiar form of control is the fact that the heart will keep on beating for many hours after all its nervous connections with the rest of the body have been severed. This condition would be very difficult to explain from the usual standpoint of the relation of nerve to muscle, were it not known, from the time of Remak, over half a century ago, that the heart muscle is permeated with a network of nerve cells and thus may be said to carry its own nervous mechanism within itself. Hence it is clear that the sympathetic and vagus nerves are not related to the heart muscle as ordinary motor nerves are to the muscles that they control, but are to be regarded as an auxiliary nervous apparatus superimposed on the heart whose true nervous mechanism may be within its own substance.

It is not my purpose to enter here into the vexed question of the nature of the heart-beat in the adult vertebrate. As you are probably aware, this question has divided physiologists 
into two opposing camps, the neurogenists who believe that the heart-beat is essentially nervous in its origin and the myogenists who hold that it is muscular in source. But quite aside from the way in which this question may be settled, one point seems to be well established, and that is that in the embryo of such a vertebrate as the chick, the heart begins to beat before any nervous tissue whatever can be discovered in it. At this stage, then, the heart-beat must be purely muscular and the nervous complications such as they are in the adult must be of later origin.

The peculiar condition seen in the embryonic heart suggests that in primitive animals muscle may have preceded nerve in its evolution, and in fact confirmation of this view seems to be presented by sponges. In these animals the presence of muscular tissue was long ago recognized, and recent studies on their activities have shown that sponges are enabled by means of this tissue to close their pores and other apertures, and change slightly the form of their bodies. They are not known to possess any nervous tissues whatever, and the responses which they exhibit, like those of the embryonic vertebrate heart, are appar- 
ently dependent entirely upon the direct stimulation of muscle.

In the adult human body there is at least one muscle which, like the embryonic heart, is open normally to a certain degree of direct stimulation. This is the sphincter pupillæ by means of which the pupil of the eye is constricted. This muscle is ordinarily under the control of the oculomotor nerve, and it responds reflexly by contracting when the retina is brightly illuminated. But it can also be made to contract by direct stimulation. If, in a blind person, a strong beam of light is thrown through the pupil on to the retina, but without illuminating the iris, the muscle does not shorten, thus showing that the ordinary reflex are is inoperative. If, now, the same beam is directed against the iris, in which the muscle is embedded, a contraction follows, thus giving evidence of the direct stimulation of the muscle. Certain parts of the musculature of our bodies, then, exhibit forms of response that are more primitive than the reflex and that indicate something of the probable nature of the beginnings of neuromuscular activity.

If the embryonic vertebrate heart illustrates 
a stage in the evolution of neuromuscular mechanisms at which no reflex can occur, the adult organ shows, in certain relations at least, a simple form of true reflex. The heart of the rabbit is invaded by a small nerve which arises as a branch from the vagus and which has been called the depressor nerve of the heart. If this nerve is cut and its peripheral end is stimulated, no result follows, thus showing that the nerve has no motor relations with the heart. If, on the other hand, the central end is stimulated, a general fall in blood pressure follows, demonstrating that this nerve is an afferent nerve whose activity induces through the central nervous system an enlargement of the blood vessels of the body. The receptor endings for this nerve are in large part in the heart and are stimulated by each stroke of that organ. When, therefore, the action of the heart is vigorous the effect on the endings of the depressor nerve is such as to call forth a general enlargement of the blood vessels of the body, thus providing the heart, in a simple reflex way, with an ample outlet for the blood. Since this adjustment goes on quite without our knowledge, it is correctly described as a reflex unassociated 
with consciousness, and in this respect is like other deep-seated reflexes such as those by which the food is moved through the digestive tube. Operations of this kind constitute, perhaps, the most primitive class of reflex movements with which we are acquainted. Although they may be absolutely unassociated with consciousness, they exhibit a nicety of adjustment that is most baffling when explanation is attempted, for they show every appearance of intelligent control. They, therefore, afford evidence for that conception of the organism which has recently been so vigorously advanced by the neovitalists, namely, that the organism continually exhibits conditions which, when we attempt to explain them, seem to necessitate the assumption of an element of intelligence.

The class of reflexes just mentioned, that is, those unassociated with consciousness, make up in all probability the large part if not the whole of the nervous life of many of the lower animals. While such a statement can be at best only a judgment without the possibility of final proof, it seems more probable that the nervous life of sea anemones, jelly fishes, and other lowly organized forms is made up of sim- 
ple nervous acts like the one just described than that these animals have any real conscious existence. They are probably much more correctly described as animal automata than as beings possessing even a low degree of intelligence.

Many reflexes of the human body take place with the certainty and precision of those just discribed, but, unlike them, are associated with consciousness. If we irritate the surface of the eye by touching it, we involuntarily wink. Here, then, is a simple reflex which is associated with an irritating sensation, though the response itself is involuntary. Sneezing and coughing are similar reflexes. If we repeatedly strike a dog on one side of the middle of the back, he will begin scratching movements with the hind leg of that side. Not only are muscles thus reflexly brought into action, but glands also serve as the efferent organs for such reflex activity. When the surface of the eye is irritated, not only does the lid move, but the eye waters, that is, there is a reflex operation of the lachrymal glands whereby tears flow. In addition to muscles and glands, eleck tric organs and luminous organs, found among fishes and other lower animals, are apparently also reflexly excitable. 
Reflexes of the kind just mentioned are almost invariably congenital. The animal is born into the world with the particular reflex mechanism fully formed and awaiting merely the appropriate sensory stimulation that the new mechanism may come into full operation. The new-born babe sucks, coughs, and sneezes without lessons or advice. Bees artificially reared, and without the example of the working hive, make perfect comb. Many female insects, mostly in response to odors, lay their eggs upon materials which are appropriate food for their young. Thus a great variety of animal responses have the qualifications of simple reflexes, and the daily life of many of the simpler forms, like the worms, crabs, insects, and so forth, are probably made up almost exclusively of this kind of activity. That these responses in the lower animals are always associated with conscious states even of a simple kind cannot be maintained with certainty, but the evidence, on the whole, indicates that most of them are like our coughing, or the flow of tears from the irritated eye, involuntary operations, but with the stirrings of consciousness on the sensory side.

The interrelations of these reflexes in ani- 
mals midway in the zoölogical scale, such as the insects, for instance, are not without interest. A fly in the neighborhood of food moves, now this way, now that, partakes of a little moisture, and, if disturbed by the approach of a person, rises in the air, circles once or twice, and settles near the food to begin again its irregular foraging. Evidently in these responses smell, touch, and sight are in continual play exciting various reflexes, no one class of which predominates over another. There is a condition of approximate balance with momentary fluctuations, now this way, now that. Catch such a fly in the hand and, after a moment, liberate it; it speeds with the utmost rapidity to the nearest window. To the casual observer the movements of the fly in foraging were of the same mixed nature as those which we exhibit in many of our daily occupations, and the rush to the window seems to be an effort to escape. But the same rush is made to a closed as to an open window, and, if the room in which the trial is made is darkened by having the blinds drawn and is illuminated by a single artificial light, the rush is made not at the window or even at the open door, if it leads to darkness, but at the source 
of light, even though the fly meets its death thereby. Clearly the movements of the fly are not so like those of a human being, after all. As the test with the artificial light shows, the animal simply seeks light, not freedom. To be sure, in most instances to fly toward the light means to escape, but the insect's behavior is rather in the nature of a reflex than of a calculated action, and in that sense lacks intelligence. The fly, like many other animals of its own rank, is ordinarily in a state of what may be called balanced reflexes, but after having been especially stimulated by being caught and roughly handled, this balance is greatly disturbed and one set of reflexes, those concerned with flight toward the light, becomes supreme. Under such circumstances the fly, without reference to food, drink, or other factor in its environment, rushes headlong at the most considerable light within its range. Of these two states, the one of balanced and the other of unbalanced reflexes, the former is more nearly representative of the condition in man, though at first sight the reverse seems to be true.

Turning to man, it is evident that, notwithstanding his many powerful and assertive 
reflexes, he is not so much within the grip of these agents as a fly is under the dominance of its own reflexes. From the standpoint of his nervous organization he is a much more truly balanced organism than a fly. His acts are not so abundantly purely reflex, but the state of his higher nervous activities suggests not only a condition of balanced reflexes, but one that might be conceived to have resulted from the disintegration of reflexes. The higher nervous life of man, his intellectual life, seems built upon two processes, the reception of impressions through the sensory mechanism of the body, and the production of voluntary acts. These two operations represent in a way the two parts of a reflex, and since they are abundantly present in the higher nervous activities of the human being in an essentially independent way, it is possible that the phylogenetic beginnings of this form of intelligence may have been associated with a disintegration of reflexes. Certain it is that our sense organs are almost continuously pouring into the central organ a varied stream of impulses indicative of the changes in the outside and yet without calling forth any obvious responses in our musculature. In a like manner, our central or- 
gans are discharging impulses to motion without having been subjected to any particular sensory stimulation. These two classes of activities are continually exhibited in our higher nervous life and afford some of its most difficult problems.

So far as our intellectual activities are concerned, our sense organs may be said to be receiving incessantly notices of external changes and to be transmitting these notices to the central organs rather as information than as incentives to action. From the eyes, the ears, from the nose, the tongue, from the organs of touch, from the cold and heat spots, from the organs of pain and the deep-lying muscle receptors, and from myriads of other and unknown sensory mechanisms a steady flow of impulses pours into the central organs. The vast volume of this flood is of no special service except in so far as it enables us, partly consciously and partly unconsciously, to adjust ourselves to the momentary state of the environment. But certain currents in the general flow influence us much more than the rest and come to be more or less permanent eddies in our mental stream. These eddies begin to catch in early childhood, and as mem- 
ories continue to accumulate throughout life till the obliterations of old age and death. In many respects this accumulation is most diverse, for from the best remembered circumstance to the fact that is just about to be forgotten there is every gradation, and apparently no circumstance remains long in the same state of vividness, but all is drifting toward oblivion, some portions more rapidly than others, while the new is ever replacing the old.

In practical life we come to regard our remembrances as having a certain degree of completeness, but in reality they are the merest shred of our past. Think of a vivid experience in the last ten years or so and recount to yourself the occurrences of the day on which it happened. Very little but the most shadowy outline is left. Even yesterday, so near at hand, is mostly gone, and as a test for the present who among us here can give again from memory the first sentence of this lecture? We all heard it and I read it, but even I cannot repeat it. Yet if memory were in this respect only as perfect as a dictagraph, this sentence could be recovered from every one in the room. I am fully aware that in certain 
unusual mental states, such as hypnosis, the individual can deliver information about matters which in his normally wakeful condition he seems to be incompetent to produce, and that in this way evidence of memory activity in the subconscious regions of the mind is adduced. But that this additional accumulation would bring the shadowy past into anything like the completeness of the present is not for a moment to be imagined. Marvelous as all these processes are, in that they are suggestive of hidden and unseen powers, we must still admit, I believe, that memory at best is a most fragmentary affair. This opinion is well expressed by Walt Whitman when, in speaking of the insufficiency of biography, he declares -

Why, even I myself, I often think, know little or nothing of my real life;

Only a few hints - a few diffused, faint clues and indirections.

But fragmentary as memory is, it is that which binds our personality together; without it social responsibility would cease to exist. We admit its frailness by translating our ideas into the permanency of the written record. This supplement to memory penetrates our 


\section{BIOLOGY AND SOCIAL PROBLEMS}

whole life, from the memorandum on a scrap of paper to the inscription on the living rock, and thus aids enormously one of our mental processes at its weakest point.

How is memory related to the nervous system? By appropriate methods of experimentation we can determine with great accuracy the tracts of the nervous system over which a given reflex runs. Is such a localization possible for memory, or is this function rather the general property of the nervous system as a whole? Strange as it may seem, memory is almost if not quite the exclusive function of one part of our nervous organs, namely, the cerebral cortex. This gray layer covers the exterior of the cerebral hemispheres and thus lies on the surface of the brain separated from the outer world by only the skull and the superimposed scalp. In man it varies in thickness from one and a half to five millimeters and covers a convoluted field, which, were it flattened out, would measure on the average 2352 square centimeters, equal to an area a little over a foot and a half square. This remarkable layer is the organ in which all our sensations arise and where the processes of memory go on. It is, therefore, the location 
of one of the most important aspects of personality.

Experimental demonstrations of this truth have been abundantly carried out. By a careful surgical operation the cerebral cortex of a bird or even of a mammal, such as a dog, can be removed and the animal can be kept alive for as much as a year or more after the operation. Such animals yield most important evidence as to the function of the cerebral cortex. After recovery from the operation, they exhibit no permanent motor disturbances, such as paralyses and so forth, and they respond to practically all forms of stimulation, but their responses are not what would be called intelligent. A pigeon from which the cortex has been removed, when placed on a hot plate will raise first one foot, then the other, and finally squat rather than fly away. A dog without a cortex will respond to a painful stimulation of the skin by a growl or a bark and will turn its head toward the spot stimulated, but will not attempt to bite. Caressing calls forth no sign of pleasure, threatening no sign of fear. In sleep there is no evidence of dreaming. Such animals thus respond to the immediate stimulus, but as 
though they were without experience and in a way essentially stupid. Memory seems to have vanished from them and with it the basis for intelligent action. The animal responds to stimulation like a nervous machine and without reference to past or future.

What it is that the cortex contains and that molds our responses into intelligent acts is our store of experience. During normal life, as we have already seen, a flood of impulses due to the stimulation of sense organs by external changes pours into the central nervous organs; many of these reach the cortex and some leave on this organ a more or less permanent impression. These elemental impressions are the materials out of which our mental life is built. All our thinking is made up of a redistribution and readjustment of these elements. From the highest flights of poetic imagination, from the aspirations of the most devout to the extreme speculations of the philosopher, mathematician, and devotee of science, all are but readjustments and derivations of this mass of incoming material. Without this spring of supply the human brain would be a barren and arid waste incapable of bringing forth signs of intelligence. The 
brain of the developing child is a veritable $t a$ bula rasa on which environment through the sense organs writes the story of life. Innate ideas there are none. The uninvaded mind is like a machine in readiness for operation, but awaiting the arrival of that first flow of power to initiate its processes. Like the lung, it stands in perfect physical readiness for action; at birth the stimulus for the first inspiration occurs and the respiratory mechanism that is to run till the end of life is started.

In stating briefly the modern conception concerning the source of the contents of the mind, I have put the matter almost in the words of Locke, but the present aspect of this subject is not based upon philosophical speculation; it is grounded upon observed fact. We know that when we sleep we revert to a condition of relatively simple reflexes and that intelligence vanishes in the assumption of the unconscious state. To induce this condition under normal circumstances, we check as far as possible all sensory inflow by lying down in a darkened, quiet situation. The impulses from the organs of touch, equilibrium, and especially of hearing and sight, having been reduced to a minimum, the activity of the 
cortex quickly subsides, and with this subsidence consciousness gives place to unconsciousness. Thus, even a mind stored with recollections lapses into unconsciousness when, under appropriate conditions, the flow of new material from without is largely reduced. Not only does the inflow of sensory impulses thus condition the activity of the normal mind, but it has also been found to be of like importance in certain abnormal cases. Strümpell's boy was a defective who was insensitive to touch, had no muscular sense, no taste, or smell, or sense of pain, and was deaf in the right ear and blind in the left eye. His sensory impulses were received therefore, chiefly if not exclusively, through the left ear and the right eye. If the left ear was stopped and the right eye bandaged, so that the sensory inflow practically ceased, he passed in a few minutes into what seemed to be a state of sleep, thus demonstrating the significance of the current from the sense organs for his mental life. The ab. normal, as well as the normal, thus gives evidence of the general conclusion that, though the mode of operation of the mind may be determined by the inborn structure of the brain, the content of the mind is supplied 
ultimately through sensory impulses from the exterior.

Fragmentary and incomplete as memory is, its performances continually excite our wonder and curiosity, and even from the scientific standpoint we are prone to speculate on the methods by which it is brought about. Our common habit of recording and storing as evidence of our experience written or printed signs has given us a figurative conception of the process of memory which is in many respects misleading. We often think of the organ of memory, the cortex, as a place in which is set aside, in some such manner as that just indicated, signs of our experience to be drawn upon as needed. But the cortex is a living portion of our body, and, like other living parts, its life is expressed better in its activity than in its structure, for its structure is forever changing. Memory, therefore, is rather a duplication of a process than the reappearance of a symbol. It is rather like a current eddy in the flow of our mental life than like a material sign. But it is an eddy which only partially represents the original and carries with it something that separates it from real present experience and marks it 
as a shadow of the past. What memory really is, however, is rather a matter for investigation than speculation. Of one thing we can be fairly certain, memory is not a general property of the nervous system, but is an operation carried on in the cerebral cortex.

This portion of the brain is also the part concerned with that second set of operations which seem to result from the disintegration of simple reflexes, namely, the voluntary acts. That the impulses to voluntary movements in man take their course from the cerebral cortex, over definite neurone tracts through the cord and nerves to the muscles concerned, is a fact well attested by anatomy, pathology, and the study of cortical localization. But it is not my purpose to undertake to trace out the nervous mechanism by which we control that enormous complication of musculature that moves when we wish to move, and that fails to act when by reason of accident or disease nerve tracts are interfered with or destroyed. Suffice it to say that the impulses for the multitude of our voluntary acts emanate from the cortex. Whether they originate there de novo, or are some delayed overtime sensory impulses making their way deliberately through the central 
organs to a final effective outcome, cannot be stated, and is perhaps, after all, a question of no significance. For the nervous system, even at its lowest physiological ebb, is never quiescent. It exhibits continuous activity. Even in sleep our muscles show a slight contraction due to a faint but incessant stimulation from the nervous centers. The passage of a reflex impulse through the nervous system, then, is not so much like a brief period of activity in an otherwise motionless machine as it is like a momentary increase of motion in a slow continuous operation. From such a continuum the voluntary impulses emerge. To seek their origin is perhaps to look for that which does not exist, at least in the definite and crystallized form in which we often think of it.

Just as memory affords a most taxing and perplexing problem for science, so the voluntary act is a process about which there is very little real understanding. The difficulty lies in its freedom. Such acts give us every evidence both outward and inward of self-control. They seem to be self-determining and in this respect to violate those principles of sequence that we find to underlie so much of nature.

Attempts have been made to show that the 
freedom of the voluntary act is not without its counterpart in the more rigid aspects of science. The answer to the question what two digits will add together to make ten is not single, but may be with equal truth any one of several; four and six is as correct an answer as eight and two. But this kind of freedom is after all a formal freedom in a mental operation rather than a freedom in a material sequence in nature.

From the standpoint of science the solution of the problem of the voluntary act, like that of memory, is to be sought in investigation rather than speculation. But the scientific study of this question must be undertaken without prejudice. Physics and chemistry are branches of science to which the biologist has come to attribute a certain fundamental importance in that organisms are believed to be enormously complex physico-chemical combinations. Day by day facts of organic nature are yielding to this conception, and such progress is being made as to give rise in the minds of many investigators to the opinion that in the end all will thus be subdued. But voluntary acts, if not incorrectly described, seem to be fundamentally contrary to the gen- 
eral principles of physics and chemistry, and are, therefore, grounds for opposition to the opinion just alluded to. However, in considering this opposition it must not be forgotten that these sciences are still in process of active growth, and that what we regard as their general principles to-day are principles developed chiefly from a study of inorganic nature. In only a most tentative way have these sciences begun to touch matter and energy as exhibited in organisms. How their principles will be modified when they really begin a successful attack on living beings remains to be seen, but that these principles will be modified there can be not the least doubt. Then will be the time to raise the question of the nature of the voluntary act and other such problems if, indeed, these problems really remain serious in the light of the new knowledge, for often what seems to be a perplexing question to-day becomes insignificant to-morrow. Who concerns himself now with the number of angels that can stand on the point of a needle?

But I cannot leave this matter of memory and the voluntary operations without considering somewhat further the part of the human nervous system in which these functions occur. 
The human cerebral cortex, as already mentioned, is a superficial layer of the brain with a thickness varying from one and a half to five millimeters and covering an average of 2352 square centimeters. This cortex is estimated to weigh about 658 grammes. It is composed chiefly of blood vessels, supporting tissues, and nerve cells. The blood vessels and supporting tissues are merely mechanical accompaniments of an apparatus the real functions of which are carried on by the nerve cells. These cells have been carefully studied, their arrangement and distribution made out, and it is estimated that in a single cortex their number is not far from 9,200,000,000. Notwithstanding this prodigious number, these cells and their processes represent only two per cent of the total weight of the cortex; in other words, the cortical nerve cells and their processes in the average man weigh about thirteen grammes. This amount represents a little less than a cubic inch of material, or, to be more accurate, it will just fill a cube whose edge is 2.35 centimeters. In a man who weighs approximately one hundred and fifty pounds, this amount of substance would represent about one five-thousandth of his 
total weight, yet this very small proportion of his body serves him as the material basis for a whole life of intelligent activity and is the part of the nervous system chiefly concerned in yielding that almost impalpable product, human personality. Had Descartes been truly scientific, and had he known in his time the anatomy and physiology of the nervous system as it is known to-day, he would have declared that the cerebral cortex and not the pineal body was the seat of the soul.

From the foregoing sketch some idea can be gathered of the significance of the nervous system for man as a social organism and of the part it plays in his daily life. From a background of simple reflexes which attend to a long range of his bodily needs, and which are unassociated or only slightly associated with consciousness, rise the superstructures concerned with his higher nervous functions such as memory and voluntary action. These general nervous functions have done more to make an individual of him than any other elements in his nature. His circulatory mechanism with its centralized heart has added much to this unity, but even such organs are secondary to the nervous system. When we reflect 
that many of the lower animals, like the sea anemones, for instance, have only the merest rudiments of a nervous system, and that this system is there concerned simply in calling muscles into action and exhibits practically no central functions, we begin to appreciate how strikingly different the conditions are in higher and lower forms. Each tentacle of a sea anemone contains its own neuro-muscular mechanism and will continue to respond to food particles after it has been severed from the body. Its action is as independent of the rest of the animal as the vertebrate heart is of the body in which it grew. But the sea anemone, instead of possessing only a few such organs as the vertebrate does, is constructed almost entirely upon this plan. Its nervous functions are most diffuse and subordinate; its chief activities are feeding and reproduction. If man can be described as an organism whose tour-de-force is intellectual, the sea anemone is one whose culminating activities are assimilation and growth. This condition of affairs is characteristic of most of the lower animals and represents unquestionably a primitive stage before which the nervous system could scarcely be said to have existed. In the higher 
forms, however, this system has far outstripped the others in its growth, till in the mammals and especially in man it has reached a position of supreme dignity. Thus the nervous system, though it originated later than some other sets of organs, has in the higher forms attained to paramount importance.

With the evolution of the nervous system and the differentiation of the cerebral cortex came the possibilities of that form of complicated intellectual life that we know in ourselves. Though less than a cubic inch of our substance is really devoted to this form of activity, it is as precious a cubic inch as any we possess. By means of it we cherish the traditions of the past; its activities include all our conscious states, our simple sensations, desires, hopes, and aspirations, our sense of shame and regret at deeds of unworthiness, our joy in generous acts, our knowledge of all these things; from it emanate the impulses to those steps which mark us as dishonest or honest, extravagant or thrifty, secretive and deceptive or frank, open, and free, cold or affectionate, in short all those signs which stand for personality. Socially no part of our body is more precious than this cubic inch of cortex. 


\section{BIOLOGY AND SOCIAL PROBLEMS}

From the cradle to the grave we work to train it. Our early childish plays and lessons are intended to awaken it into activity. The school, the college, the university work upon it; our whole educational system is devised to bring into full efficiency this cubic inch of our body. It must be enriched with experience ; it must be trained to make wise decisions, to call forth acts of friendly service. If you have doubts of the enormous social significance of this cubic inch of nervous tissue, look upon the individual in which it permanently breaks down, a useless member of society, a charge upon the state, if not upon the race. 


\section{II \\ HORMONES}

Is olden times the theory and practice of medicine was more or less permeated by the doctrine of the humors. Those of you who are conversant with medical history will recall that, according to this doctrine, there were supposed to be four cardinal humors: blood, yellow bile or choler, phlegm, and black bile. Many distempers of mind and body were attributed to disturbances in these fluids, and their conditions and proportions were supposed to determine the physical and mental qualities as well as the disposition of the individual. Various kinds of insanity, known under the general name of melancholy, were supposed to be associated, as this term implies, with the black bile. And we still describe temperaments as sanguine, choleric, or phlegmatic. But with the growth of our knowledge of the nervous system and with the recognition of its significance as the chief means of control for the body as well as the seat of person- 
ality, the doctrine of the humors was relegated to the rubbish heap of worn-out ideas and disappeared from view. Within late years, however, this doctrine, in principle at least, has been revived, and recent investigations promise to give it renewed life, though not of such general scope as it once enjoyed. The fluids circulating in the bodies of animals, including man, are undoubtedly highly important and significant means of controlling the responses of these forms and of determining their states, mental and otherwise. Among the recent discoveries which have been important in opening up this point of view are those concerning the action of the pancreas, a gland which was supposed to be brought into activity through the ordinary channels of nervous reflex.

The pancreas is a long, narrow gland extending from the neighborhood of the spleen on the left side of the abdomen to the right side of that cavity where its duct opens into that portion of the small intestine known as the duodenum. This opening is three or four inches from the outlet of the stomach, therefore near the beginning of the duodenum, and very close to the opening of the bile duct from the liver. The pancreas is popularly known as 
the sweetbread, or, better, the stomach sweetbread, to distinguish it from the thyroid gland which is called by butchers, from its location, throat sweetbread.

The pancreas in man produces a copious secretion, as much as from five hundred to eight hundred cubic centimeters per day. This secretion is poured into the duodenum through the pancreatic duct and is one of the most important digestive juices. It aids in the solution of almost all the constituents of our food. The pancreatic juice is apparently produced in small amounts continuously, but the major production and discharge is associated with the taking of food. The increase of production begins soon after food has entered the stomach and develops to a maximum in from two to four hours; it then gradually falls off with the completion of digestion.

Almost two decades ago it was shown that when acid solutions were applied to the mucous surface of the duodenum, the flow of pancreatic juice was excited, and as the natural contents of the stomach are acid, it was believed that, after they had passed into the duodenum, their acidity was the normal stimulus for the reflex mechanism controlling the 
pancreas. As the food arrived in the duodenum from the stomach, the contained acid was supposed to stimulate the nerve terminals in the mucous membrane of that portion of the intestine and thus to set up nerve impulses which were reflected back from the central organs to the gland as excitants of its activity. This opinion was consonant with the fact that artificial stimulation of the vagus nerve was followed by pancreatic secretion. But the secretion of juice by the pancreas was subsequently shown also to occur even after the nerves which supply that organ, namely, the vagus and the splanchnic, were cut.

The difficulty thus introduced was removed by the work of Bayliss and Starling about a decade ago. They demonstrated that if some of the mucous membrane of the duodenum was scraped off and mixed with a weak solution of acid, an extract could be obtained which when injected into the blood would call forth an active secretion of pancreatic juice even in an animal in which the nerves to the pancreas had been severed. Hence they concluded that the secretory activity of the pancreas was not necessarily dependent upon nerves, but could be induced by a substance 
which resulted from the action of the acid food on the mucous walls of the intestine and which was taken up by the blood and in this way carried to the gland. Thus, what seemed to be a reflex action proved in reality to be the effect upon one organ of a substance formed in another. The particular substance in the case of the pancreas is known as secretin. This substance is not of the nature of an enzyme, for it is not destroyed by boiling or by treatment with alcohol. It is, however, a representative of what is probably a large class of substances now recognized under the general name of hormones, whose function it is to excite activity in organs usually situated at a distance from the region in which the given hormone is produced; in other words, to enable one part of the organism to control another and distant part. As is shown by the pancreas, hormone action strikingly simulates in its results nervous activity, and yet on an entirely different principle, a principle which in fact revives the discarded doctrine of the humors.

The extent to which hormones control the body is only just beginning to be appreciated. For a long time anatomists have recognized 
in the higher animals, including man, a number of so-called ductless glands, such as the thyroid gland, the pineal gland, the hypophysis, the adrenal bodies, and so forth. These have often been passed over as unimportant functionless organs whose presence was to be explained as an inheritance from some remote ancestor. But such a conception is far from correct. If the thyroids are removed from a dog, death follows in from one to four weeks. If the adrenal bodies are excised, the animal dies in from two to three days. Such results show beyond doubt that at least some of these organs are of vital importance, and more recent studies have demonstrated that most of them produce substances which have all the properties of hormones. A number of these organs, like the thyroids, the adrenals, and the sexual glands, have been studied from the standpoint of their internal secretions and have more than a passing biological interest.

The thyroid gland in man consists of two moderately large lobes closely applied to either side of the windpipe just below the larynx or Adam's apple. As previously stated, the gland is popularly known as the throat sweetbread in contrast with the stomach sweetbread or 
pancreas. The two lobes of the thyroid are united across the front of the windpipe by a narrow band of their own substance, the socalled isthmus. The thyroid gland is intimately associated with a group of glands, the parathyroids, whose presence was not always recognized by the earlier investigators. Some of the confusion which entered into the earlier physiological work on the thyroid was probably due to the accidental removal of the parathyroids with the thyroid, a condition which leads to very different results from those observed in the simple removal of the thyroid itself. The circumstances which brought about an investigation of the thyroid may now be briefly stated.

In any large community individuals appear from time to time who from childhood on fail to grow and develop. They therefore are of dwarfish stature, their hands are large and misshapen, their features dull and expressionless. All these signs, together with the actions and habits of such individuals, give the impression to the casual observer of low mental capacity, if not idiocy, and such in truth is their real state. As members of society they are usually more or less helpless and are either 
private or public charges. They have long been known under the name of cretins.

An examination of the physical condition of these persons has disclosed the significant fact that they all possess deficient thyroid glands, and this discovery has led to the assumption that the thyroid produces a hormone which is essential to the growth and development of the normal person. This belief is abundantly supported by the success with which cretinism and tendencies toward cretinism can be in large part counteracted by thyroid treatment. Many of our so-called defective children are known to be cases in which thyroid activity is reduced, and they approximate in many ways a mild form of cretinism. In these cases, as well as in true cretinism, the feeding of the patient with thyroid material, with the throat sweetbreads of sheep, has been followed almost invariably by most beneficial results both physical and intellectual. In this way children on a downward path of development have been rescued from a trying form of dissolution.

Defective thyroids, however, are not limited to childhood; they may appear in adult life. At this stage they cannot, of course, produce 
cretinism, but in other respects they call forth the same set of changes; intelligence declines even to dementia; bodily activity subsides till only animal sluggishness is left; a condition known as myxedema supervenes, after which in the course of some years the cases terminate fatally. These mature cases are also immensely alleviated by the thyroid treatment. In cases of myxedema it was found that injection of thyroid extract under the skin, or better still, simple feeding of thyroid material, gave favorable results. Only from sixty to one hundred and thirty milligrams of substance administered every three or four days was found sufficient to keep a patient in health.

I cannot better picture to you the significance of this treatment both for the child and the adult than by quoting from Moore the words of a well-known medical authority, Dr. William Osler, who, in speaking of this side of medicine, has said: "Our art has made no more brilliant advance than in the cure of these disorders due to the disturbed function of the thyroid gland. That we can to-day rescue children otherwise doomed to helpless idiocy, that we can restore to life the hopeless 
victims of myxedema, is a triumph of experimental medicine." "The results as a rule are most astounding - unparalleled by anything in the whole range of curative measures. Within six weeks a poor, feeble-minded, toad-like caricature of humanity may be restored to mental and bodily health. The skin becomes moist, the pulse rate quickens, and the mental torpor lessens." Thus thyroid deficiency, with all its sad consequences for the individual and society, can be largely overcome by the simple introduction into the body of an appropriate material from the outside.

But man is not only open to troubles from deficient thyroids; he may also suffer from the excessive activity of these glands. In the disease known as exophthalmic goitre the patient is nerved up to a high pitch of excitement, the eyes protrude, and in general the symptoms are the reverse of those exhibited by cases of deficient thyroid. This state can be more or less artificially produced by excessive thyroid feeding, and the disease thus imitated, as well as that dependent upon deficient thyroids, is important for us in showing how essential for our welfare and efficiency in the social organism is the proper amount of that hormone 
which is produced by a few ounces of glandular tissue in our necks.

Another important set of organs in the production of hormones are the adrenal bodies. These are paired, gland-like bodies situated in the fat, one at the anterior margin of each kidney; hence their name. Each adrenal body consists of an outer, firm, yellowish layer, the cortex, and of an inner, soft, gray or brownish mass, the medulla. Like the thyroid, the adrenals are unprovided with ducts. As already mentioned, their removal from an animal is invariably followed by its death in a few days or even hours. They have long been known to be associated with an obscure, fatal disease, known as "Addison's Disease," which is marked by the appearance of bronze patches upon the skin. From their medullary portion there has been extracted a substance variously named epinephrin, adrenin, or adrenalin, and capable of producing profound bodily changes. This substance is apparently normally present in the blood in very small amounts. If a strip of intestine is placed in a warm oxygenated Ringer's solution, it will show rhythmic contractions. If, now, to one hundred million parts of this solution only one part of adre- 
nalin is added, these contractions cease and the bit of intestine relaxes. On the basis of such observations as this, it has been estimated that the adrenalin in our blood is normally about one in two hundred millions.

Adrenalin has been isolated and is well known chemically. It has in fact been produced synthetically. It is important as a means of checking hemorrhages in minor surgery, for, on local application, it quickly brings about a constriction of the walls of the blood vessels.

No one knows with certainty what purpose the small, constant amount of adrenalin in the blood serves, but when more of this substance appears, certain profound and significant changes occur. These changes may be stated briefly as follows: a cessation of the activities of the alimentary canal; a notable shifting of the volume of the blood, from the abdominal organs, to the lungs, heart, central nervous organs, and limbs; an increased cardiac vigor, an augmentation of the sugar content of the blood; a hastening of its power to coagulate; and a rapid recovery of muscle from the condition of fatigue. At first sight this seems to be a heterogeneous assembly of physiological effects such as might constitute a formal de- 
scription of the action of any substance on the body. But such is not in reality the case. As Cannon has pointed out, all these facts gather around a central condition of no small biological interest, namely, preparation for physical struggle. The cessation of abdominal activity and the transfer of blood to the lungs, heart, nervous system, and limbs is an adjustment whereby the nutritive fluids are concentrated in regions important for muscular activity. Increased cardiac vigor improves the circulation in these regions. The increase of sugar in the blood adds to its nutritive value for muscular work. The quickened coagulability serves as an increased safeguard in case of injury. And the improvement in recovery of muscle from fatigue lengthens the time during which an animal may continue a struggle. Thus all the changes induced in the body by an increase of adrenalin in the blood may be regarded as emergency measures for times of intense struggle. It is, therefore, entirely natural to find that the extra adrenalin necessary for all these changes is produced by the glands whenever the animal is driven into a condition of fear, rage, or pain. These nervous states reflexly excite in the adrenal bodies 
such a production of adrenalin that the conditions already described are almost immediately present; in other words, when an animal is excited to fear or rage or subjected to physical pain, its whole neuromuscular mechanism and related parts are thrown into a condition most favorable for vigorous and protracted response. The biological significance of this set of relations from the standpoint of the struggle for existence must be clearly evident, and we see again how a highly complex system of organic interrelations can be developed on a principle other than that of nervous control.

Just as the thyroid and the adrenals can exert a profound influence on the activities of the body through their hormones, so the sexual glands can effect changes in a like manner and quite independently of their usual products. This subject has been worked upon recently with very interesting results by Steinach. The method employed by this investigator was as follows: Young male rats and guinea-pigs were first castrated, after which the ovaries from a young female of the appropriate species were grafted under the abdominal skin of each castrated male. The animals 


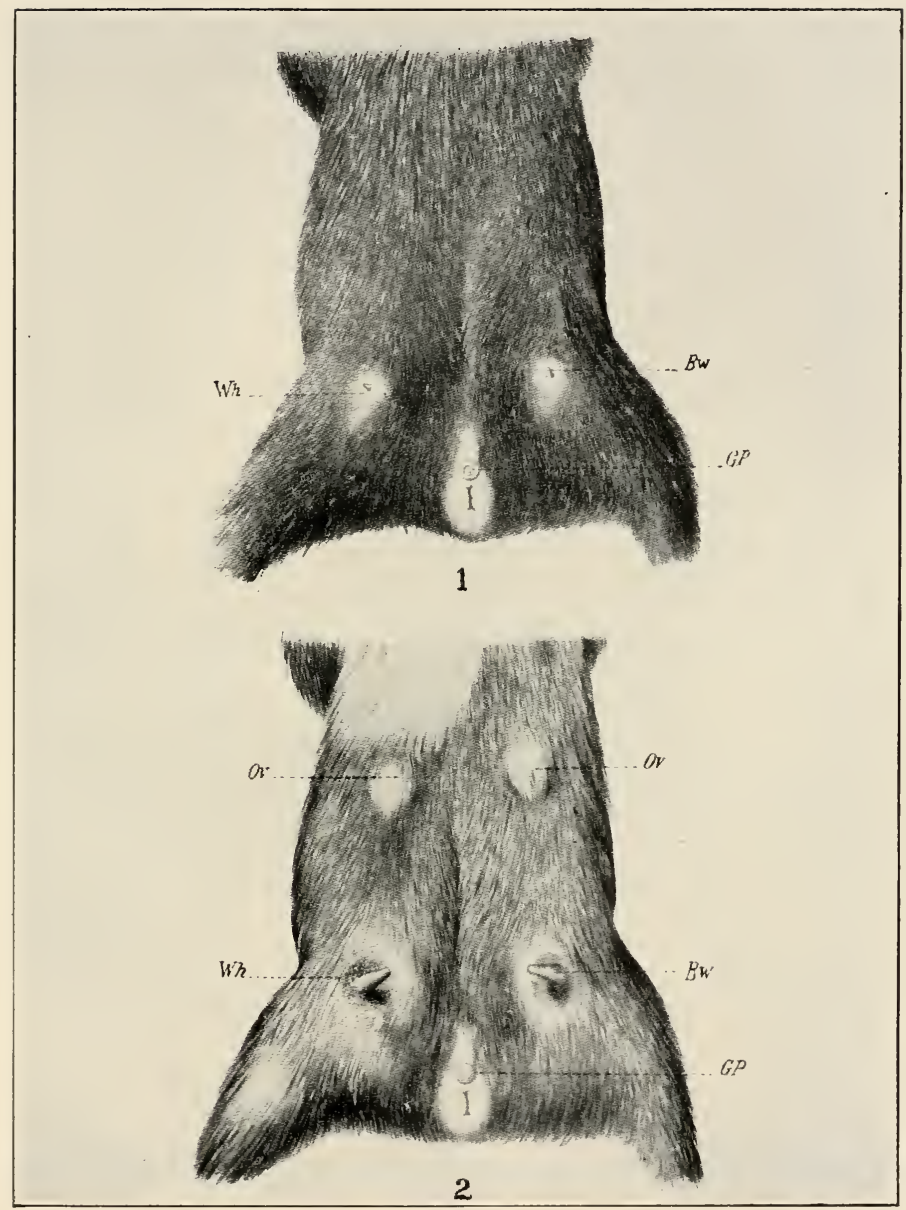

After Steinach

\section{PLATE I. FEIINIZED GUINEA-PIGS}

Fig. 1. Normal male guinea-pig. Fig. 2. Feminized male guinea-pig. Bw, nipple; GP, glans penis; $\mathrm{Ov}$, position of implanted ovary; $\mathrm{Wh}$, areola. 

were then allowed to grow to maturity and the development of the secondary sexual characters was closely watched. (Plate I.) The implanted ovaries, even though simply under the skin, grew and ripened. None of these animals developed male secondary sexual characters; the male external genitalia, for instance, remained immature, and the body assumed the form of the smaller sex, the female. The growth of hair and the deposition of fat were in the direction of the female type. The mammary glands, the nipples, and their surrounding areolæ were typically female. None of these animals showed the characteristic male sexual excitability even in the presence of a female in heat. They very commonly did exhibit the "tail reflex" and the " protective reflex," both characteristics of the female, and they were sought by males, though of course ineffectively. Thus, so far as the secondary sexual characters were concerned, a male animal had been converted, both structurally and functionally, into a female.

When in a very young male animal the testes were transplanted from one region to another, development was seen to proceed along normal lines. Such an animal in the 
course of time assumed all the male secondary sexual characteristics and exhibited sexual desire. On examining its transplanted testes, however, it was found that all the reproductive cells had disappeared and that the interstitial cells had crowded in and taken their place. For this reason it is believed that the hormones which are given out by the reproductive glands, and which serve to excite the development of the secondary sexual characteristics, are not the products of the germ cells proper, the egg cells and sperm cells, but come from the interstitial cells which are in no wise concerned with reproduction.

Enough is known concerning operations and transplantations in the human being to justify the conclusion that the results obtained by Steinach on the lower mammals will be found to apply with full force to man. The complete removal of the ovaries from a woman is always followed by a premature menopause. In the case of a woman who had been for two years without ovaries and who during that period had not menstruated, the successful grafting into her body of a live ovary from another woman was followed by a return of menstruation and sexual desire. The profound 
effect of castration on the male body, as seen in the eunuchs of the East, is too well known to require comment. All these instances show that the effects of the reproductive hormones in man are quite as profound and significant as they are in the lower mammals, and that in time we may expect to see confirmation in man of many of the facts already ascertained for these lower forms. Not only is this to be expected, but it is reasonable to suppose that the solution of some of the social questions with which human civilization is beset to-day may well be formulated on the basis of such observations as those of Steinach already alluded to.

In fact, one of the important social problems turns on the very points that have just been discussed. The question is as to the best method to be employed in the sterilization of defective males. Two general lines are possible, either castration, that is the complete removal of the reproductive glands, or some such operation as the cutting of the spermatic ducts or other treatment whereby the reproductive cells are eventually destroyed. Both methods render the individual incapable of having offspring, but, judging from Stein- 
ach's results on the guinea-pigs and rats, the first would probably also profoundly change his character, in that among other things he would lose sexual desire, whereas the second would leave him much the same as he had been except as to this ability to form sperm cells. Thus, depending upon what society wished as a result, one or other course might be adopted.

Another interesting line of hormone activity of broad, biological significance is that of the relation of the mammalian embryo to the mother. It is well known that as the mammalian embryo matures many preparatory changes take place in the maternal body. Prominent among these are the steps taken by the mammary glands in preparation for the flow of milk which must be in readiness for the young at birth. How are these preparatory changes initiated? It is well known that there are no nervous connections between the mother and the embryo, and if the latter influences the former it must be through some such means as hormones. Working upon this suggestion, Starling and Lane-Claypon attempted to ascertain whether in the rabbit the embryos gave out hormones which gradually brought 
the mammary glands into activity. To test this hypothesis, they made an extract from a number of rabbit embryos and injected this subcutaneously into virgin female rabbits. The result of this treatment was that the mammary glands of these rabbits underwent the preparatory growth that would have been characteristic of them had there been a real pregnancy. Further evidence of the same kind is furnished by the interesting case of the Blazel sisters, to quote from Howell. These twins were joined like the Siamese twins; they had a common circulation but separate nervous systems. Pregnancy and parturition in one was followed by a secretion of the mammary glands of both. Thus it seems quite clear that the developing mammalian embryo gives out hormones to the maternal body and that these hormones excite activity in those maternal organs which are to serve the young after birth. It would be superfluous to point out here the significance of these relations to the practice of dairying. In my opinion a step has been taken in the laboratory which when properly followed up may revolutionize our methods of dealing with the milch cow. The time may not be very distant when an extract of calf 
may be more generally effective than the bull.

Even from what is known at this early stage in the study of hormones, it must be evident that they are most important substances for the correlation of one part of the body with another, and that in certain instances they may rival though they never equal in importance nervous methods of correlation. Of course the whole plan of hormone interrelation is such that nothing can be expected to spring from it, as the higher nervous functions have grown from the simpler nervous operations; but, from the instances cited, it must be clear that next to the nervous system nothing will be found so potent for the control of animal activity as the hormones.

In much of the preceding account, I have dealt with the nervous system and the hormones as though they were distinct and separate means of accomplishing very similar ends. But as might be suspected by any one who is conversant with the conditions in organisms, both means are often most complexly and intricately interwoven in the performance of a single act. This is well illustrated in our respiration. Nothing seems simpler or 
easier than the regular filling and emptying of our lungs with air, and yet the operation is carried on in a way that illustrates practically all the forms of nervous and hormone action of which I have spoken.

The muscles concerned with the respiratory movements are those of the lower neck, the chest, and the upper abdomen. They are controlled from a pair of centers closely connected and lying in the midst of the medulla oblongata. Although these centers can be influenced from almost any part of the central nervous system, they will continue to give out impulses to respiratory movements even after they have been separated from practically all afferent tracts. This independence of afferent control has led to the conclusion, well supported from other directions, that the respiratory centers are stimulated by the quality of the blood that passes through them. It has been shown that when the blood that reaches them is very impure, their action results in vigorous breathing, and that when it is more nearly pure, they subside in their activity or even cease altogether. The constituent of the blood which is effective in this respect seems to be the carbon dioxid, and, as this is 
produced in many parts of the body, it may be regarded as the hormone for the respiratory centers. Thus a somewhat regulated interaction between the amount of carbon dioxid in the blood and the activity of the respiratory mechanism takes place, in that with an increase of carbon dioxid comes an increase in the activity of the respiratory mechanism whereby the organism is relieved of this excess of waste. Thus an equilibrium between the amount of carbon dioxid and the efficiency of respiratory movement is quickly established.

But the respiratory rhythm is not one dependent simply upon carbon dioxid. The lungs are supplied with afferent nerve fibers which make their way to the central organs through the vagus nerves, and when these nerves are cut the respiratory movements are considerably changed, becoming slower and deeper. Under normal conditions a given respiratory movement apparently stimulates these afferent fibers in such a way that they bring about in a purely reflex fashion a hastening of the next response. Thus this reflex mechanism has a marked influence on the respiratory rate.

Although the respiratory movements ordinarily proceed without relation to voluntary 
operations, we know that within a certain range, we can alter them to suit our will. They may be hastened, or slowed, or stopped altogether, though not indefinitely; in other words, they are more or less voluntary. The respiratory movements then include not only hormone control, but reflexes of the simplest class and willed actions, a range which, as I intimated before, involves almost every form of control known in the body.

The fact that hormone action is often combined with nerve action brings us face to face with the ancient doctrine of the humors. These were supposed to determine personality in a way already indicated. Many substances produced in the body, though not specifically hormones, may affect our cerebral cortex in such a manner as to color our whole lives, in fact determine our temperaments. We all recognize the passing effect of tea, coffee, or alcohol. When these materials are not taken in sufficient quantities to prove poisonous, they serve as intellectual alteratives, and the temporary condition called forth by them leads us to suspect that the naturally vivacious or taciturn person may have within him a spring that generates unceasingly the appropriate 
humor. Every one is familiar with the feeling of utter exhaustion after protracted strenuous physical exercise. Probably most of you know that if the blood of a dog in this state of overwork is transfused into the body of a rested $\mathrm{dog}$, the second animal shows all the signs of lassitude that the first one did. Thus excessive muscular exercise must change the composition of the blood in such a way that when it acts upon the conscious centers, it generates those vague sensations that we describe as utter tiredness, a condition which can be easily interpreted from the standpoint of the hormones. These substances, then, not only interrelate distant parts and activities of the human body as in its simpler phases the nervous system does, but they play the part of the ancient humors, and color momentarily or even permanently that aspect of our nervous systems which we call temperament. 


\section{III \\ REPRODUCTION}

REPRODUCTION is one of the most characteristic and fundamental activities of living things. Almost every organism, plant or animal, possesses this power during some period in its life. In a few instances it is lacking, as, for example, in the worker bee, a sterile female, but in the vast majority of plants and animals it is characteristically present. Every species must contain at least certain individuals concerned with this function, else the species would become extinct.

The methods by which reproduction is accomplished are extremely diverse. In the simpler instances the fully grown body of one individual divides into two and thus produces material for two new individuals. Examples of this kind occur among the unicellular animals and the simpler multicellular forms such as the corals, worms, and the like. The more complex methods of reproduction are accomplished by means of two kinds of cells, 


\section{BIOLOGY AND SOCIAL PROBLEMS}

and these are usually produced by different individuals. Individuals that produce sperm cells are called males, those that produce egg cells, females. The production of a new individual is initiated as a rule by the fusion of a sperm cell from one individual with an egg cell from another. For obvious reasons this method of reproduction is designated as sexual in contrast with non-sexual reproduction, which is the term used for the simpler type.

Sexual reproduction is the common method of increase among the multicellular animals, especially the more complex forms, but it cannot be said to be entirely absent from the unicellular organisms. In man reproduction is accomplished almost exclusively by the sexual method, there being only a few somewhat obscure and rare occurrences that can be interpreted otherwise.

When we reflect on the enormous structural complexity of the human body, its countless myriads of cells appropriately disposed to form its organs, and particularly when we attempt to realize the immense variety of processes which go on within it, many of which are essential to its continuance, it seems as though a reproduction of such a complex 
would be open to so many accidents and fraught with such difficulties as to be well-nigh impossible. And yet, with every well-born child that comes into the world, this is accomplished. But a human being is vastly more than a successfully adjusted complex of cells whose activities are sufficiently intricate and adaptable to meet with success the ever-changing conditions around it. A human being is a vast sum of conscious past experience, a longing, desiring creature that seeks to mold the future, a dreamer in hours of wakefulness, a thing of affections and feelings. And this side of man's nature, too, is reproduced. But by what process? As in former cases we shall attack this problem from its material side. What are the physical conditions under which reproduction is accomplished?

William Harvey, the discoverer of the circulation of the blood, in his treatise on generation published in 1651, maintained that " even on the same grounds, and in the same manner and order in which a chick is engendered and developed from an egg, is the embryo of viviparous animals engendered from a preëxisting conception." This " preëxisting conception" was in Harvey's mind the exact 
equivalent of an egg and justified the phrase used in the earlier part of his treatise and so often associated with his name, "Omne vivum ex ovo," every living thing from an egg. To this declaration, as Harvey explicitly states, the human being is no exception. But it was not vouchsafed to Harvey to see the egg of man or of any other viviparous animal except dimly in his mind's eye.

The egg of the mammal was discovered late in the spring of 1827 by Von Baer. The first egg seen was that of a dog, but subsequently the eggs of other mammals, including man, were found, and an account of the whole research was published in the latter part of that year. This matter-of-fact statement of an investigation, the repetition of which would be a simple affair in the hands of even an elementary student to-day, gives no idea of what it cost its discoverer. In his autobiography Von Baer speaks of the physical strain and damage to health from the long hours he spent over his microscope and his worktable, and because of his reluctance to leave his workshop, he compares himself to a hermit crab. "And so it happened," he says, "that in the course of a year, I shut myself up in my shell while the 
snow was still on the ground, and when I again ventured out to cross the garden wall only a hundred steps from me, I was astounded to find that the fields of rye were in the ear." This is the application and energy that brought to light the mammalian egg. The fact is a commonplace now, but let us not forget that it took a genius to point it out to us.

The human egg is a minute spherical body just about visible to the unaided human eye. It has a diameter of about one fifth of a millimeter. Aside from a slight envelope, it is composed of a mass of protoplasm containing some fine yolk granules and a spherical nucleus whose diameter is about one seventh or one eighth that of the whole structure. Thus the human egg, like that of many other animals, exhibits all the characteristics of a simple cell.

The two ovaries of a woman shortly after the onset of puberty are estimated to contain seventy-two thousand so-called primitive eggs, of which, it is believed, not more than about four hundred become mature and are discharged. These mature egg cells are liberated with more or less regularity over the period of sexual maturity. This is ordinarily from 
about the fourteenth to the fiftieth year, though the fact that pregnancy may occur as early as the seventh year shows that occasionally puberty begins very early. As a rule only a single egg cell is discharged from the ovary at each period of ovulation, but, as the condition of multiple births shows, there may possibly be as many as seven eggs freed at once. Quintuplets have occurred often enough to place this number beyond doubt, and there have been apparently a few good cases of sextuplets. An instance of seven at a birth is said to be recorded in Hameln-an-der-Weser, in Germany, on a memorial tablet of the year 1600 , and this, so far as I can ascertain, is the largest well-authenticated number of children delivered at a birth, for the case of eight reported in 1872 from Trumbull County, Ohio, seems on good authority to be spurious. Although, as we shall see presently, there is good reason to believe that some eggs divide in a way to give rise to more than one child, it is likewise well established that many multiple births are due to the liberation of several eggs; how many as a maximum cannot be stated, but from the cases just quoted it is not necessary to assume more than seven. In such in- 
stances the total number of eggs discharged by a woman in the course of her life would probably be several times four hundred, but the ordinary rule seems to be a single egg at each of the four hundred or more ovulations. You are probably aware that the discharge of the egg is supposed to take place periodically and to be related to menstruation, but if there is an exact relation between these events, it has yet to be discovered.

As it is the characteristic of the female to produce egg cells, so it is that of the male to produce sperm cells. The human sperm cell, or spermatozoön, as it is commonly called, was discovered in 1677 by Hamm, a student in Leyden, whose master, Leeuwenhoek, gave an accurate description of it. In man each spermatozoön is a minute, elongated, lashlike body, one end of which is somewhat enlarged. The whole has some resemblance to a much attenuated tadpole. Each spermatozoön measures ordinarily about one twentieth of a millimeter in length, or roughly a quarter of the diameter of the human egg. Its enlarged end corresponds to the nucleus of a cell, and its lash to the protoplasm, so that the spermatozoön, like the egg, is a single cell, though its form 
at first sight is not so suggestive of this comparison.

The testes in man produce spermatozoa more or less continuously from the beginning of puberty, at about the fifteenth year, on to old age. Spermatozoa are often absent in old men, but they have been found in individuals as late as the ninetieth year. It has been estimated that in the period of thirty years between the twenty-fifth and the fifty-fifth year of manhood, one individual will produce the prodigious number of $339,385,500,000$ spermatozoa, a number incredibly large compared with the egg cells probably liberated by the normal woman during her sexually active life.

When the human egg cell is fully formed, it is discharged on the surface of the ovary, whence it makes its way down the Fallopian tube toward the uterus and the exterior. If it is not fertilized, it disintegrates and is lost, but if copulation has occurred and sperm cells abound in the tube, one may enter the egg and thereby fertilize it. The fertilized egg then passes down the Fallopian tube into the uterus, where, instead of disintegrating, it attaches itself and develops into an embryo and eventually into a fully formed child. 
It is evident from these brief statements that the two parents supply very unequal amounts of material to the offspring. The father contributes merely one spermatozoön whose volume is surely not over 50 cubic micra or thousandths of a millimeter; the mother contributes the substance of the egg cell, which, if it be regarded as spherical and with a diameter of 150 micra, would have a volume of $1,767,150$ cubic micra, or over 35,000 times that of the sperm cell. Not only is this true, but the mother likewise contributes from the substance of her body all the nourishment that enables the diminutive egg to grow to a fully formed babe. Hence the material of the child's body is vastly more maternal than paternal in its origin.

Notwithstanding the disparity between the amounts of material contributed by the two parents to the offspring, it is well established that in any population as a whole the children show about as much resemblance to the father as to the mother; in other words, in inheritance the mother has no more influence than the father. This condition has led to a closer scrutiny of the actual contributions of the two parents. 
The mature egg about to be fertilized represents all the material of maternal origin at this early stage in development. This material consists of the protoplasm of the egg and of certain nuclear bodies called chromosomes because of the ease with which they become colored in artificially stained preparations. These chromosomes are peculiar in that they are very constant in number for the eggs, sperm, or other cells of a given animal. In the human being, because of the unfavorableness of the material and of the difficulty in getting it in a well-preserved condition, the number of chromosomes has probably not been finally determined. According to the researches of Winiwarter, published in the last few years, the number of chromosomes in the ordinary cells of the human body is fortyseven in the male and probably forty-eight in the female. As just intimated, however, these determinations may not be final, but whatever the number may actually prove to be, it is probably not far from what has just been mentioned. It is remarkable that in practically all animals the number of chromosomes in the mature egg cell is half that found in the ordinary cells of the body of the female for the 
given species. Hence in man we would expect the number of chromosomes in the mature egg cell to be twenty-four.

In the operation of reproduction the father contributes a spermatozoön which, when it enters the egg, carries with it a negligible amount of protoplasm, a minute body called a centrosome, and a group of chromosomes essentially like those from the mother, and about equal to them in number. Thus the fertilized egg consists of protoplasm almost entirely from the mother, of a centrosome from the father, and of chromosomes in about equal numbers from each parent. If children always took after their mother, we might suspect that part of the fertilized egg which came exclusively from the maternal side, namely, the protoplasm, to be the bearer of hereditary traits. If they regularly took after the father, we might, with equal right, suspect the centrosome as the organ of transmission. But as children take more or less after both parents and as the only parts of the fertilized egg which are derived from both sources are the chromosomes, these bodies are believed to be the means by which inheritance is accomplished. If this opinion is correct, one must conclude that all 
those details of stature, color of hair, facial and bodily form, inborn acts, and other traits that make the child resemble the parent are dependent upon this infinitely small amount of living substance which is thus handed on from parent to offspring. Although this doctrine is not without its opponents, it is so well substantiated in many ways as to have gained very general credence.

One of the recent lines of evidence that supports this view is that touching on sex determination. From the most ancient times the question of sex has been one of great theoretical and practical interest, and many hypotheses have been advanced and advice of all kinds has been sought and given without resulting in any evident control over this matter in either man or the lower animals. Many have believed that the resting posture of the body of the mother during pregnancy or the character and amount of the food given her would determine the sex of the developing child. But all such theories were rendered very improbable by the occurrence of identical twins, triplets, quadruplets, and so forth. In man ordinary twins usually have separate sets of fœtal membranes and always separate 
chorions. They give every evidence of having descended separately from two fertilized eggs. They may be of the same or opposite sex. After birth they resemble each other no more than any other two children in the same family. Identical twins, on the other hand, possess only one chorion and are otherwise so related to their foetal membranes as to give evidence that they have descended from a single egg. They are invariably of the same sex, and in after life they are commonly very similar in appearance. This similarity is often so marked as to lead to their confusion even among their near associates; hence the ludicrous situations furnished by the two Dromios and their masters in "Comedy of Errors" as well as by their classical progenitors, the Menæchmi. Identical twins are never of opposite sex, as Viola and Sebastian in "Twelfth Night," who, though "born in an hour," must have been descendants from separate eggs, if not the pure product of a poet's imagination. The fact that identical twins are always of the same sex, and that ordinary twins may or may not be, shows that sex determination must be an operation that occurs in the very early stages of development and before the material ordinarily des- 
tined to give rise to one individual divides in the case of identical twins into two. Therefore the subsequent history of the embryo, such as the position afforded it in the mother's body or the character and amount of nourishment provided for it, can have no influence on its sex.

This interpretation of the condition in man is abundantly supported by recent work on one of the primitive mammals, the armadillo. It was long ago known that all the young in a single litter of this animal were of the same sex. Newman and Patterson have recently shown that in the armadillo only one egg is discharged from the ovary at each period of heat, and that, if this egg is fertilized, four embryos usually result, all of the same sex. These four embryos, to use Morgan's statement of the case, are more like each other than like the embryos of any other litter, or even more like each other than they are like their own mother. In other words they are identical quadruplets exactly comparable to identical twins in man. The fact that they are always of the same sex and are positively known to come from one egg cell supports most completely the conclusion arrived at from the study of human twins. 
It is the process of forming two or more human embryos from the substance of one egg that has given color to the statement that man does exhibit at times non-sexual reproduction, for the differentiation of two or more embryos from the mass of cells that would ordinarily produce a single one is apparently a process of budding, and in this respect it may be maintained that man occasionally reproduces non-sexually.

But this aspect of identical twins, interesting as it may be to the philosophical zoölogist, is of much less significance than that which touches on the determination of sex. This operation is not only known through the condition in identical twins to be associated with a very early stage of development, but evidence from certain lower animals, chiefly the insects, indicates that it is involved in the very earliest stages of the differentiation of egg cells and sperm cells. This is well illustrated in Protenor belfragei, an insect closely related to the squash bug. When the ordinary cells in the body of the female of this insect divide, the number of those peculiar nuclear bodies known as chromosomes is seen to be fourteen. In the formation of the egg cells, as might be 
expected, these chromosomes become reduced in number to half that characteristic of the cells of the body; in other words, each mature egg cell contains seven chromosomes. When the ordinary cells in the body of the male of this insect divide, the number of chromosomes is seen to be thirteen, one less than in the female, and when the spermatozoa in this animal are formed, the reduction in the original number of thirteen results in the formation of two classes of sperm cells, one with seven chromosomes and the other with six. These sperm cells are formed in equal numbers and are apparently the means of sex determination. For, when an egg with its seven chromosomes is fertilized with a sperm having the same number, an individual arises whose body cells exhibit fourteen chromosomes, and such animals are females. When, on the other hand, an egg is fertilized by a sperm with only six chromosomes, an individual whose body cells contain only thirteen chromosomes results, and the animal is a male. It is thus clear that in this instance the fertilizing spermatozoön determines the sex of the offspring and that the material which is concerned in this is that contained in the chromosome. Not 
only are the chromosomes thus concerned with sex determination, but from the fact that they possess somewhat different forms, there is reason to believe that a particular chromosome is responsible for this determination. Thus in Protenor an especially large chromosome is always found in those sperm cells that have seven such bodies, that is, in those that produce females, and it is as regularly absent from those that produce males. Hence this chromosome is sometimes called the sex chromosome.

Sex determination from the point of view just presented has been studied in many other animals and, though the process presents a great variety of details, it seems to turn regularly on the chromosome composition of the reproductive cells. In man, as already stated, the reproductive elements are not so favorable for this kind of study as in many other animals, but within a few years Winiwarter has shown that human spermatozoa, like those of Protenor, are probably of two classes, one characterized by the presence in each cell of twenty-three chromosomes and the other by twenty-four such bodies. If this is true, sex determination in man is brought about prob- 
ably by the same means as in animals like Protenor, in that when the human egg is fertilized by a sperm with twenty-three chromosomes a male results and when by a sperm with twenty-four chromosomes a female is the outcome. If, as in insects, the two kinds of spermatozoa in man are about equally numerous, we can understand why male and female human births are so nearly equal in number.

From what has been stated concerning the composition of the fertilized egg and the nature of sex determination, it must be clear that the chromosomes are most significant bodies in inheritance, in fact they seem to be the vehicles of this process. The reason we inherit from our two parents those characteristics of feature and action which mark us as their descendants is because they have each contributed a certain number of chromosomes to our make-up.

Simple as this statement is, when we face the full actualities of the case, it strains even the imagination. That so small an amount of material as that represented in the chromosomes of the fertilized egg should influence in so rigid a way so large an amount as that contained in the adult body seems almost incredi- 
ble. The human egg is approximately a sphere with a diameter, in the case of a large example, of about one fifth of a millimeter, and with a specific gravity about that of water ; consequently its weight must be about 0.004 of a milligram. The volume of the chromosomes in a fertilized mouse egg has been determined to be somewhat less than one thousandth of the volume of the whole egg, and, assuming that this proportion hold for the human egg, and that its chromosomes have about the same specific gravity as water, the weight of this material would be about $0.000,004$ of a milligram. Yet this minute amount of substance is believed to determine to a nicety that infinity of adult traits wherein a man resembles his parents. If we assume the weight of the average human being to be sixty-five kilograms, then the weight of the determining material to that which is determined is as 1 to $16,250,000,000,000$. In attempting to grasp this almost inconceivable relation, it must be borne in mind that the material of the chromosomes in the egg is living and that, in the growth of the individual, it assimilates and increases in volume like other living material; it is not spread through the growing body in 
ever increasing dilution. Nevertheless it is this extremely minute amount of material in the egg cell that gives rise to that which determines in the adult.

The fullness of this determining power is seldom appreciated for the reason that, in ordinary births, we have nothing as a standard whereby to judge of the looseness or rigidity of the process of inheritance. But in identical twins, triplets, and so forth, one individual in each group may be taken as a standard for the rest in the group, and we can judge from the similarity of the members in a single group how closely the process works. Wilder gives us good evidence on this point taken from a set of identical triplet girls by a person who was familiar with them. This person described them in the following terms: "I have seen twins that looked very much alike, but I could see a difference when they were together. I could not see any difference in these triplets when they stood in a row before me, and I never saw any one else who could, except their mother. She said she could, but I doubted it; they used to fool her often. When they were babies she kept different colored beads around their necks to tell them by. They always 
weighed on the same notch until they were seven years old, then one gained half a pound more than the others." When they were little girls, one of them confided one day to a friend that she had been bathed three times that morning, while the others confessed that they had not been bathed at all, an accident that emphasized their complete bodily identity at that period. Their lives must have been, indeed, a modern "Comedy of Errors." But for us they are significant in that they show how enormously powerful in determining traits was that infinitesimally small amount of chromatic material contained in the one microscopic egg from which they all came, a power which when spread through three persons instead of one seems still to be undiminished. But we must remember that the human body, like that of many other animals, is often very sensitive to minute amounts of material. Cats are known to be affected by 0.0001 of a milligram of adrenalin, and our olfactory organs are stimulated by $0.000,000,002$ of a milligram of mercaptan. Is it, therefore, after all, so surprising that $0.000,004$ of a milligram of chromatic material should have so profound an influence on our development? Small as these amounts 
are, they are far from molecular limits, for Von Frey has calculated that the extremely minute amount of mercaptan which we can just smell contains about a fifth of a billion of molecules. Nevertheless, as compared with the smallest amount of material that the physicist or chemist can weigh directly and accurately, namely, about 0.001 of a milligram, the amounts of the various materials just mentioned are undeniably small.

We have thus seen how each human being starts life from a minute egg cell charged with an infinitesimally small amount of material which is destined to determine with surprising accuracy his configuration and responsiveness. The process that the egr cell undergoes in changing into an adult person is first of all cell division. The simple spherical egg cell divides by a somewhat complex process into two cells, and these into four, and so forth, till the millions upon millions of cells which constitute the adult body are formed. At each division the chromosomes divide and are shared by the descendant cells so that both maternal and paternal influences are handed on to each cell in the growing individual. The great aggregate of cells which thus constitute the adult 
body, and which are all descendants from the single original egg cell, falls naturally into two classes ; first, somatic cells, such as those which form the skin, muscles, bone, nerve, and other parts of the adult body, and, secondly, the reproductive cells, the egg cells in the female and the sperm cells in the male, which are destined to give rise to new individuals. Of these two sets of cells the one which by its collective arrangement and activity exhibits those aspects of the child wherein it shows its likeness to its parents are the somatic cells, and the discovery of the way in which these cells become impressed with the parental traits is one of the chief problems of genetics.

Before 1900 scarcely anything of value in genetics could be said to have been in the hands of the working biologist, but with that year the discovery of Mendel's writings, lost for about a generation, gave to the study of heredity such an impetus as it had never experienced before. The Mendelian principles, to which this revival is due, are already popularly known. You are aware that inheritance in accordance with these principles is accomplished by the association of characteristics related in pairs and that these characteristics 
appear in the offspring unmixed and in highly significant proportions. Thus in guinea-pigs the white coat-color of a pure albino stock and the black coat-color of a pure melanic stock can be made to associate by crossing these two stocks. The animals that result from this cross are not, as you well know, gray individuals midway between the white and black parents, but all strictly black individuals to all appearances like their black ancestor. That they are not, however, exactly like this ancestor is seen from the fact that when they are bred among themselves, instead of producing nothing but black individuals as their black parent would have done if mated with his kind, they bring forth pure white stock as well as black stock and in the proportion of one of the former to three of the latter. Thus these black individuals can be shown to carry hidden in their bodies the white characteristic, though they show nothing of this on their exteriors. Of such pairs of characteristics, the one which may thus be hidden is spoken of as recessive, the other dominant. (Plate II.)

The black and the white descendants of such individuals occur in the very remarkable 


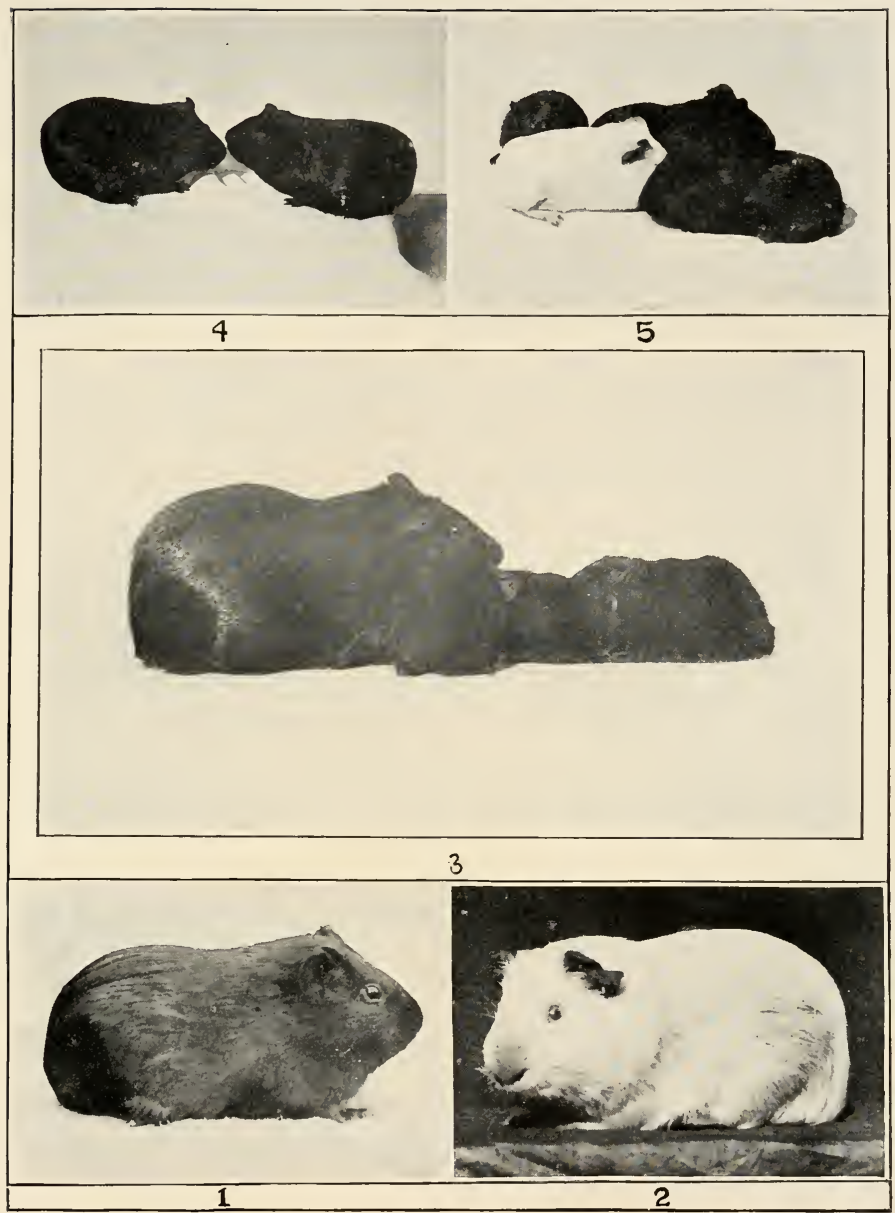

All figures after Castle

\section{PLATE II. MENDELIAN INHERITANCE}

Fig. 1. A black female guinea-pig. Fig. 2. An albino male guinea-pig. Fig. 3. A black female guinea-pig with young by an albino male such as that shown in Fig. 2. Fig. 4. Adult black guinea-pigs from a litter such as that shown in Fig. 3. Fig. 5. Albino and black guinea-pigs whose parents are shown in Fig. 4. 

proportions just mentioned and present conditions of great interest. The twenty-five per cent of white individuals, when bred among themselves, have been proved to be pure whites like their white grandparent. The seventyfive per cent of black individuals, when tested in a like fashion, have been shown to be, in the case of twenty-five per cent, pure black like their black grandparent, and, in the case of the remaining fifty per cent, black but with the ability to produce white offspring exactly as their parents did. Thus the grandchildren of the original pure black and white mating fall into three classes: twenty-five per cent pure white, twenty-five per cent pure black; and fifty per cent black, but capable of producing a definite proportion of white offspring.

You are familiar with the explanation that Mendel offered for this remarkable state of affairs, an explanation that is still generally accepted. Briefly it is to the effect that each reproductive element, egg cell or sperm cell, can carry only one of any pair of characteristics, and that in this respect each reproductive cell, be it either egg or sperm, is pure. If we assume this segregation of characteris- 
tics together with the principle of dominance, we shall find it easy to understand the conditions just mentioned for the guinea-pig.

In the original pair of animals for such a series of breeding experiments as have been briefly mentioned, it makes no difference how the sexes are combined; the male may be white or black, the outcome will be the same. But for simplicity we may assume that the male is black and the female white. As each individual comes from a pure stock, the male will produce sperm cells, all of which will carry the black characteristic, and the female, for the same reason, will produce egg cells, all of which will carry the white characteristic. Their offspring, then, will be the product of a white egg, so to speak, fertilized by a black sperm. Such animals, as is well known, are always black in color. But as already indicated they possess within them the recessive white characteristic. If we assume, now, that their reproductive elements are pure like those of their parents, then we should expect each male of this stock to produce, not one kind of sperm, but two, one with the white characteristic and the other with the black, and that these elements would be present in equal numbers. The 
same would hold true of the females; each one would give rise to equal numbers of black eggs and of white eggs.

If, now, we imagine these two kinds of eggs to be fertilized by the two kinds of sperm and that the combinations be purely fortuitous, we would expect four classes of fertilized eggs of equal frequency; once in four a white egg would be fertilized by a white sperm, once in four a black egg by a black sperm; once in four a black egg by a white sperm; and once in four a white egg by a black sperm. The first class would yield the twenty-five per cent of pure white individuals, the second the same per cent of pure black individuals, and the third and fourth the fifty per cent of black individuals which are, however, capable of producing white as well as black offspring. Thus the assumption of the purity of the germ, the segregation of characteristics, makes clear these very remarkable proportions as seen in the actual experiments in heredity.

The conception of the hereditary process which has grown out of this idea and the way in which this process is supposed to have impressed itself upon the face of nature is well seen in the mutation theory 
of De Vries. According to De Vries the significant hereditary differences between individual organisms, plants as well as animals, depend upon the presence of unit characters, so called, such as those of black or white coatcolor in the example of Mendelian inheritance just described. These unit characters were believed by De Vries to be of a stability comparable with that of the chemical elements; there were no intergrades. Many of these unit characters are known, and every individual organism can be regarded as a special combination of them. Thus animals and plants can be grouped in accordance with the unit characters that enter into their composition; all those having the same unit characters constitute what De Vries calls an elementary species and when they differ in this respect they belong to different elementary species. Thus, guinea-pigs that differ in coat-color, like the examples previously cited, would constitute two elementary species separable by the specific unit characters of black and of white coat-color. It is to be observed that the conception of elementary species is quite different from that of the old Linnæan species. Two members of the same elementary species, 
such, for instance, as two black guinea-pigs, may produce offspring some of which may be black and some white. In other words, members of one elementary species may have in their immediate offspring members of other elementary species. Thus the idea of continuity of breed, usually attached to the definition of a Linnæan species, is quite absent from that of the elementary species. But the main fact that underlies the whole De Vriesian conception is the fixity of unit characters. That there is a large body of truth in this, for certain characters at least, cannot be denied, but that the difference is comparable with that between chemical elements, as originally claimed by De Vries, is far from probable. Evidence on this point comes from a number of sources, but I shall cite only one instance.

The hooded rat is a domesticated form in which the fur is dark over the head and down the middle of the back, but is otherwise lightcolored. Thus the rat has the appearance of a light animal wearing a dark hood. When this stock is crossed with the uniformly dark wild rat, the hooded character is found to behave as a Mendelian recessive; that is, in the first generation of descendants all individuals 
have the coat-color of the wild parent, but of their progeny one fourth show the markings of the hooded stock. This hooded character, then, is what may be called a unit character.

Castle has attempted to ascertain whether this unit character can be modified by a process of selection, the object being to produce from the hooded stock by selection two extreme conditions: a completely light animal, and a completely dark one. In the beginning there were selected from the common hooded forms, two sets of individuals: one with as little pigmentation as possible, the other with as much. These two sets afforded the material with which the test began. Their descendants were selected in the desired directions generation by generation till, after somewhat more than six years of work on over twentyfive thousand rats, two clearly divergent stocks were produced. One of these was composed of members entirely light except for a small amount of dark on the head, and the other was made up of individuals completely dark except for some light on the belly. Thus two stocks were obtained that bred true and approximated closely to the two extremes aimed 


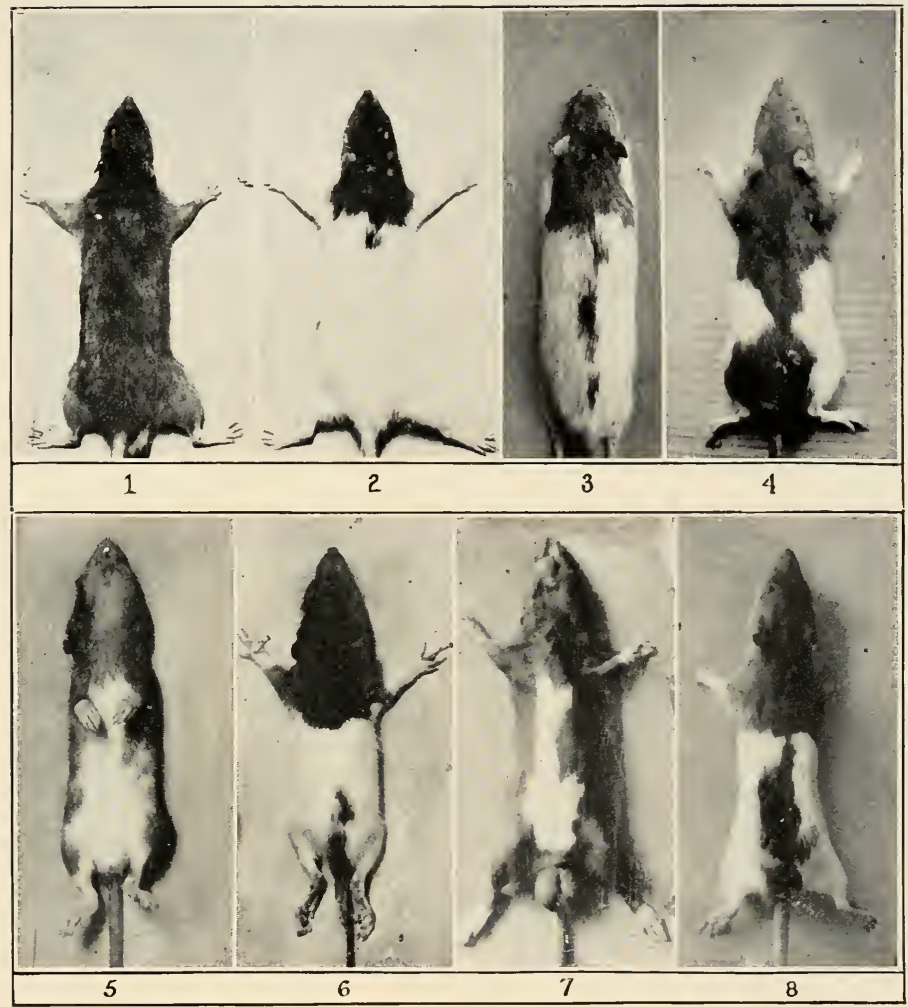

All figures after Castle

\section{PLATE III. UNIT CHARACTERS}

Fig. 1. A wild gray rat. Fig. 2. A hooded rat with the hood much reduced by selection. Fig. 3. A normal hooded rat. Fig. 4. A hooded rat with the hood much extended by selection. Figs. 5 and 6. Grandchildren from such animals as those shown in Figs. 1 and 2, which they respectively resemble. Their parents were like the rat shown in Fig. 1. Figs. 7 and 8. Grandchildren from such animals as those shown in Figs. 1 and 4, which they respectively resemble. Their parents were like the rat shown in Fig. 1. 

at, if they did not absolutely arrive there. (Plate III.)

Does this condition indicate that the unit character of the original hooded stock has gradually been pushed along in one derived stock in one direction and in the other in the opposite, or is this whole change a purely superficial one and does the unit character still remain in both stocks unmodified? An answer to this question was found by crossing females from each extreme stock with a single wild dark male and by breeding grandchildren separately from each of the two sets of descendants. Under such circumstances we should expect to find that three fourths of the grandchildren of both sets would be dark and that one fourth in each set would show the condition of the hooded character. Such proportions were practically realized, and the hooded individuals in the two sets were found to be, not like the original hooded stock, but like their modified grandparents. The hooded individuals from the light grandmother were mostly light; those from the dark grandmother, mostly dark. These results show that a unit character is not necessarily fixed, as De Vries originally maintained, but can be 


\section{BIOLOGY AND SOCIAL PROBLEMS}

modified in that it may be gradually moved, by selection, for instance, in one direction or another. Marvelously stable as the unit characters are, they are not in their stability comparable with the chemical elements, for they exhibit gradual changes. Whether these changes are to be accounted for on the basis of inherited modifiers, a kind of additional demon behind the demon unit character, or by some other process, is a question for the future to decide. Of one point we can feel fairly certain, unit characters are modifiable.

Although these results have been worked out almost exclusively on the smaller, rapidly breeding animals, there is no reason to suppose that they do not apply with full force to the human being. Already a long list of characteristics, which are inherited in man in accordance with one form or another of the Mendelian principles, is known. This list includes certain eye colors; certain hair colors and hair forms, such as straight, wavy, and curly; certain skin colors, such as that of the blond and the brunette; pale, fresh, and colored complexions in the white race; stature, form of head, and nose in certain races ; musical and non-musical temperaments; various 
deformities and defects, such as short fingers, aborted fingers, split fingers, split foot, cataract, certain hair deficiencies, stationary nightblindness, certain sex-limited diseases like hæmophilia, and color-blindness; and certain kinds of deaf-mutism, insanity, and imbecility. Thus even at this early stage in the study of human heredity, there is good reason to believe that many of our traits Mendelize.

But the question that confronts the modern student of genetics is the extent to which Mendelism may be said to apply. Are all characteristics in man and other animals inherited in accordance with these principles, or are only a part of them so handed on? Man himself seems to offer some very interesting examples that are very difficult to bring under the Mendelian rules. Thus, when the white man is crossed with the negro neither one nor the other is produced, but an intergrade, the mulatto. Inheritance of this kind is called blended and is represented by many examples. Whether it is a form of Mendelism in which dominance is absent is not clear. Possibly it is a totally different method of inheritance from that exemplified in the Mendelian cases. Certainly so long as instances of this and other 
forms of inheritance remain unanalyzable from the Mendelian standpoint, we may conclude that this explanation does not exhaust the field of heredity. But even if Mendelism is an explanation of only a part of the phenomena of heredity, it represents an advance in all respects the most important that the science of genetics has yet made, and it opens up a prospect to the experimentalist which is no less alluring than it is full of promise.

Notwithstanding the fragmentary character of our knowledge of reproduction, we know that a child takes after its parents because the fertilized egg from which it has grown is made up of living material part of which came from each immediate ancestor. The amount of all the material in the egg is immensely small compared with that of the person who develops from it, and the amount of that material in the egg concerned with heredity is probably not over a thousandth part of the whole egg; nevertheless this infinitely minute quantity of material, rather than the environment, stamps upon us with an iron hand the configuration of our early life, a configuration which is so rigidly determined that where two or more individuals come from the same egg almost 
complete identity results. Yet this operation of the rigid transfer of traits from individual to individual is an essential step, perhaps the essential step, in the process of racial progress. Without it the evolution of man would have been impossible. In the last lecture I shall endeavor to show the relations of this process of reproduction to that of evolution as seen in the human species. 


\section{EVOLUTION}

Assuming that the population of the globe is about sixteen hundred millions and that the average length of human life is forty years, a number that represents the present condition in only the more favored states and nations, about forty million persons must die annually. Of such persons those who reach maturity have usually gathered about them material devices as protections against the inclemencies of nature and as means to their personal comfort. Such persons, moreover, in the course of their lifetime develop or acquire lines of action which yield continuance of life and happiness. At their death their material property is commonly inherited by other members of society, often those to whom the deceased had blood ties; their lines of action, remembered or otherwise recorded, serve as examples for avoidance, imitation, or improvement. Thus, generation by generation, the composition of human society changes, its material acquisi- 
tions accumulate, and its combined forces and activities turn now this way, now that. We think of the totality of these changes as taking place through a process of evolution by which not only novel features arise, but the rich inheritance of the past is preserved and handed on. When we reflect on the means by which this social growth is accomplished, we are driven to admit that it is in reality the individual man. He it is, who, working with his fellows, accomplishes all. What he inherits, what he devises, what he can hand on, these are the elements that make up the totality of social evolution. Did we but know with certainty how all this change comes about, many of our most momentous social problems would be solved.

To many naturalists of the Darwinian period an experimental laboratory for the study of evolution would have seemed to be resources thrown away. These older workers supposed evolution to proceed at so slow a pace that an experimental investigation of it would be impossible, but for somewhat over a decade and mainly in consequence of the discovery of Mendel's writings, the study of evolutionary problems from the experimental standpoint has 
made great progress. In fact, since the opening of the twentieth century a more substantial advance has been made in the solution of evolutionary questions than in the whole period between 1859, the year in which the "Origin of Species" was published, and 1900.

But the Darwinian period of evolutionary activity was not the first. It was preceded by a series of preliminary skirmishes fought out mostly upon French soil. In 1809, Lamarck, then about sixty-five years old, published his "Philosophie Zoologique" in which was contained the first well-ordered attempt at a general theory of organic evolution. But this fell on unsympathetic ears. It was, moreover, opposed by Cuvier, whose scientific authority was such that the whole movement for the time being was swept aside, and Lamarck, in a measure unrecognized and after an old age of blindness, died in 1829 .

But among the French contemporaries of Lamarck, to quote freely from Delage, was Etienne Geoffroi Saint-Hilaire. He it was who in 1830 took his stand against Cuvier in the Academy of Sciences in a sensational debate which lasted almost six months, a duel, so to speal, between the theory of transmutation 
and the theory of the invariability of species. This controversy became noised throughout the scientific world. Goethe, then eighty-one years old, took a keen interest in it and devoted his last work, completed in 1832, to a review of the debate, pointing out its great scientific and philosophic import. Yet the outcome of this far-famed contest was not favorable to the new ideas. In the opinion of the majority, the victory remained on the side of Cuvier, and the doctrine of transmutation lost ground.

The general theory advanced by Lamarck contained much of significance and importance, and was in part accepted by Darwin. In recent years it has been revived, at least in certain particulars, by those who class themselves as Neo-Lamarckians. Lamarck was much impressed by what he believed to be the direct effects of the environment upon organisms, particularly plants, and he attributed evolution in the main to changes in this factor. His idea of the way in which animals had been transformed was through what might be called the indirect rather than the direct influence of the environment and may be briefly stated as follows : changes in an animal's surroundings in- 


\section{BIOLOGY AND SOCIAL PROBLEMS}

duce changes in its habits, and changes in its habits bring about changes in its structure. Be these structural changes ever so slight, if they recur regularly from generation to generation and are accumulated, they will eventually so modify an animal that a transmutation of species may be said to occur. Thus in an indirect way the ever changing environment is responsible for animal transformation.

The Lamarckian hypothesis, thus stated, appeals to the student of evolution through its simplicity and directness. The ease with which we may induce modifications in our own bodies by voluntary change of habits is too well known to require comment. The special exercise of a set of muscles induces an increase in their size and that of all their connected parts, and the reverse of this is followed by their shrinkage and decline. What could be simpler than to conceive of a given animal being what it is in consequence of its own activities and those of its race? Such an animal may be assumed to possess its present form in consequence of its racial habits.

The application of this hypothesis to man is most readily and easily accomplished, and few organisms can be shown to afford a bet- 
ter apparent example of its mode of action than the human species. The considerable influence that the kind of life that an individual leads has upon his body has long been well recognized, and the direct effect of this, favorable or unfavorable, on his offspring has underlain the claims of the moralist for generations past. Thus the Lamarckian hypothesis, though an impersonal explanation of transmutation, can be easily brought into relation with man's higher nature and made to point a moral.

But a very serious obstacle to the acceptance of this hypothesis has gradually arisen in the otherwise easy path of the Lamarckian. The slight changes which nearly every organism exhibits as the effects of its environment and which, for Lamarck, are the actual steps in evolution, are as a matter of fact just the class of changes in favor of the inheritance of which there is the least evidence. Any peculiarity that an animal exhibits and that is not an inheritance, but is the result of an individual change due either to an alteration of habit or to the direct influence of the environment, is called an acquired character; and the assumption that acquired characters are 
inherited is a most doubtful biological proposition.

The clarification of this whole matter, and the present attitude of the majority of biologists toward it, are the results chiefly of Weismann's work. Weismann pointed out very clearly that the multitude of cells that arose by the division of the egg cell, and that eventually constituted the body of an adult animal, could be grouped into two sets, the somatic cells and the germ cells. The somatic cells are represented by those cells that give rise to skin, bone, muscle, nerve, and other non-reproductive tissues. They constitute the great mass of the body and carry on all its functions except that of sexual reproduction. The germ cells are those that give rise to sperm cells or egg cells, and that are therefore primarily concerned with reproduction. Both the germ cells and the somatic cells in any individuals are descendants of the $\mathrm{egg}$ cell from which that individual arose, but they are not derived one from the other. Germ cells are cells that are differentiated directly from certain of the unmodified cells that result from the division of the egg cell and never from cells that begin to show a tend- 
ency to become somatic cells. In a similar way, somatic cells are never derived from cells which have begun to assume the character of germ cells, but are also directly derived from the segmented egg. The two classes of cells are thus fundamentally distinct, and it is not inappropriate to describe the body of one of the higher animals as composed of an enormous aggregation of somatic cells in which is harbored and protected a certain number of germ cells.

What has been defined as acquired characters, namely, those changes which are not the products of inheritance, but which are the direct results of some change in the environment or in the activities of an animal, are necessarily alterations in its somatic cells. The change in a muscle in consequence of a new form of exercise is a change in somatic cells; the alteration that the skin exhibits under a new exposure is of the same kind; the change in the nervous mechanism by which a new habit is established is also somatic. If acquired characters, then, are modifications in the somatic cells, and these cells are distinct from the germ cells, it is difficult to see how a change which may affect a group of somatic cells, 


\section{BIOLOGY AND SOCIAL PROBLEMS}

skin cells, for instance, can so influence the germ cells of the same animal as to produce the newly acquired trait in its offspring. That the germ cells are influenced by the somatic cells there can be not the least doubt, but that this influence shall result in reproducing in the somatic cells of the offspring exactly the condition acquired by the corresponding cells of the parents is almost inconceivable. Since there is no known means either in descent or otherwise of transferring the changes which occur in the somatic cells of an individual to its own germ cells so as to insure that these changes may be handed on as such to its offspring, Weismann was led to suspect that acquired characters were not inherited, and that, therefore, the Lamarckian hypothesis, natural and simple as it appeared on the surface, was untenable.

The experimental evidence that has been gathered concerning this question has been largely in support of Weismann's contention. One of the first lines of experimental work to be instituted in this direction was that on mutilations. The tails of rats and mice were cut off generation after generation with the intention of discovering whether this process tended 
to induce a shorter tail in the descendants. All such experiments yielded absolutely negative results and fell in line with what was known of the oft-repeated mutilations of the human body as, for instance, in the Jewish practice of circumcision. From observations of this kind it was soon concluded that such acquired characters as mutilations were not inherited.

The effects of changes of temperature on one generation and their inheritance by the next were likewise tested. Certain butterflies, when in the pupal stage, were subjected to abnormal temperatures and in consequence the wing-markings were much modified. These changes were shown to be inherited by their descendants. But it was pointed out with correctness that the pupal insects on which the abnormal temperatures acted carried in their bodies, almost fully formed, the germ cells for the next generation, and that these germ cells were just as much open to the effects of the change in temperature as the somatic cells of the parent were. Hence such instances were set aside as not crucial.

The same is true of the effect of light in producing pigmented individuals of the sala- 
mander Proteus. This inbabitant of eaves when reared in its natural dark surroundings is without much pigment and consequently of a delicate flesh-tint. When reared in the light, it develops a well-marked dark coloration. The newly born descendants of such dark parents emerge at once as dark individuals as though this peculiarity had been transmitted to them from their parents. But as Kammerer, who has recently studied this problem, has pointed out, the body of Proteus is so translucent that the light can reach and affect its germ cells and thereby influence the next generation, as well as modify its somatic cells. In consequence of this semi-transparency light can affect the interior of Proteus as a temperature change can that of most lower animals. Possibly in some such way as this are to be explained Kammerer's later results on the spotted salamander of Europe. This animal becomes lighter in color when reared on a light clay background and darker when reared on a darkearth background, and the descendants of two such stocks show at once the parental acquisitions. Kammerer regards this as a conclusive case of the inheritance of acquired characters, but before it can be so accepted, it must be 
shown beyond the vestige of doubt that the germ cells are not affected in some such way as that assumed for Proteus, and the observations themselves should be confirmed by other workers. These experiments, like those on mutilations, though they have yielded interesting material, have not yet produced indubitable evidence of the inheritance of acquired characters.

If such characters were really inherited, it ought not to be difficult to show that the somatic cells of a given animal can exert a considerable influence on the germ cells contained within the body. Experimental attempts in this direction have been made by the transplantation of ovaries. Magnus removed the ovaries from a black rabbit and grafted into their places those from an albino rabbit. The black rabbit was then paired with a white male and gave birth to two offspring, one white and the other black. A similar experiment was then tried by Guthrie on the hen and with similar results. Both these experiments were, however, inconclusive, for the stock on which the tests were made was not well known and its purity, therefore, was not established. Castle and Phillips, in 1911, reported similar experiments 
on pedigreed guinea-pigs and with results of a more conclusive character. I shall state these in Castle's own words: "A female albino guinea-pig, just attaining sexual maturity, was by an operation deprived of its ovaries, and instead of the removed ovaries there were introduced into her body the ovaries of a young black female guinea-pig, not yet sexually mature, aged about three weeks. The grafted animal was now mated with a male albino guinea-pig. From numerous experiments with albino guinea-pigs it may be stated emphatically that normal albinos mated together, without exception, produce only albino young, and the presumption is strong, therefore, that had this female not been operated on she would have done the same. She produced, however, by the albino male three litters of young which together consisted of six individuals." "The first litter . . . was produced about six months after the operation, the last one about a year. The transplanted ovarian tissue must have remained in its new environment, therefore, from four to ten months before the eggs attained full growth and were discharged, ample time, it would seem, for the influence of the foreign body upon the inheritance to show itself were 
such influence possible." All the young were black. The white body of the foster mother, then, had no influence on the transplanted egg cells, thus demonstrating in this respect the independence of germ cells and somatic cells in one individual. (Plate IV.)

The evidence from experiments on the inheritance of mutilations, as well as on the transmission of changes of a more normal kind, and from observations on the effects of a foster parent body on transplanted egg cell, is thus unfavorable to the view that acquired characters are heritable. If such characters are inherited, it ought to be easy to demonstrate the truth of this proposition, but the fact that there is not a single unequivocal case in its favor, though the proposition has been tested in many ways, is much against it. The adverse evidence is all negative, and though conclusive negative evidence is most difficult to obtain, that which is at hand is so strongly negative that, inviting as the proposition is, the inheritance of acquired characters cannot be said to be supported by present-day biological observation.

That man is not an exception to the rule just laid down seems at first sight startling, 
if not absurd. To maintain that what we acquire during life has no effect upon our descendants seems to be flying into the face of observed fact and, if true, to remove one of the main springs that activate social progress. That the right or wrong course of the parent's life flows on more or less through that of the child is one of the fundamental beliefs of human nature and has long been held out by moralists as an incentive to upright living. This doctrine, however, seems to be in direct opposition to the attitude of most modern biologists toward the question of the inheritance of acquired characters. But the contrast thus set up, when carefully scrutinized, is found to be not a contrast, after all, but rather a confusion due to the complexities of human inheritance.

The transmission of traits from parent to offspring, as we see it exhibited in guinea-pigs and other organisms, is so like the transmission of property from parent to child in everyday life that we call both by the same name, inheritance. But we must never forget that the inheritance of property is the original process and that the other is but a figure of speech. That there are fundamental differ- 
ences between the two cannot for a moment be doubted. In the inheritance of property the same article is passed on from parent to child, but in what we call inheritance in sexual reproduction, the part inherited is not passed on from the parent through the egg to the offspring, but only a tendency or activity representing such a part. Moreover, as we have already seen, such tendencies do not even emanate from the parental part in question, but come directly from the racial store contained in the germ cells. Thus it must be evident that the inheritance of property and the inheritance of traits are very different processes, and, since both occur in the human being, it is important that, though we use the same name with which to designate them, we keep the two processes clearly separated in our minds.

That the inheritance of property in the ordinary sense of the word is a most significant factor in human affairs needs no comment. It is, however, a practice that few other animals have adopted. Ants continue to inhabit the same hill generation after generation and thus inherit and enjoy the results of their ancestors' labors. Other social animals may afford similar 
examples, but the instance par excellence of the inheritance of property is to be found in the human species. As a social proposition this practice has its advantages, though its effect on many individuals in removing their incentive to normal activity shows that the curse of the Nibelungs' hoard is more than a poetic fancy.

But is everything that we inherit from our parents either an object handed down to us in a physical sense or a tendency or other indirect influence transmitted to us through the egg? Probably not! A large part, perhaps the larger part, of what we are accustomed to say makes up our lives is obtained neither as an inherited object nor as a transmitted tendency, but has reached us in a somewhat different way. What comes to us over this third route may be put briefly as our heritable intelligence. As I pointed out in the first lecture, the mind of the young child is an unwritten page on which the environment, acting through the sense organs, inscribes the story of life. Much of the sensory inflow is controlled and directed by the parent, and thus in the early stages of life he can exert a most profound influence on the personality of the child. With the 
awakening of the emotions and the development of attachments, the parent usually comes to be an example to the child, and imitation adds greatly to the obvious similarity of the two minds. With the development of mental independence on the part of the offspring, the parental attitudes and acts may, however, prove repugnant to the maturing individual and lead to some courses of action directly the opposite of those of the ancestor. Thus, a dissimilarity, which, however, may rest upon a more deep-seated agreement, may make its appearance; the children of the over-religious may seek irreligion; those of the drunkard, total abstinence. Into the quickening mind of the developing individual, with its growing knowledge, its expanding sympathies, and its increasing capacity for action, the inheritance of the race is poured; knowledge representing the past experience of mankind with all the power it gives, the imagery of times gone by with its capacity to awaken the emotions, in short the total record of human effort in so far as it is preserved. This race inheritance comes to us from human memory, from the written page, and from a thousand other sources. It meets us on every side, but it is 
the special office of our educational institutions to preserve it and hand it on. From the child at the knee to the university student, all are learning from the same general source. Thus the process of acquisition goes on, and as a result we expect an individual not only with a well-stored mind, but capable of using his mental equipment in the performance of serviceable acts, the broadening of sympathies, and the discovery of new truths.

Such a result is the exclusive outcome of neither one nor the other of the two methods of inheritance that we have described. If we designate that through the germ cell as organic and that by direct transfer as social inheritance, we can say that our intellectual outfit comes to us more in the nature of a social contribution than of an organic one. The content of the mind is not congenital; it is a vast mass of subsequent acquisition. It is in every sense a veritable body of acquired characters. It is, therefore, not to be expected that it will ever become hereditary. The rudiments of learning must be acquired by all ; even the genius must begin with the alphabet; and there is no reason to suppose that the time will ever come when a pedigreed birth certif- 
icate will take the place of a college entrance examination. As educators our task is limited only by the supply of human beings. The automobile may drive out the horse, but the educator, whatever the community may think of him, has come to stay.

If, however, the content of the mind is of the nature of acquired traits and hence not heritable, the mental machinery by which this content is handled is, in part at least, hereditary. The inheritances of feeble-mindedness, insanity, and other defects, as well as of favorable traits, such as predisposition to music and so forth, are too well established as germinal features to admit of dispute. They resemble a more stable background on which our somewhat plastic natures rest, and, though their well-being is essential to our success, they of themselves afford only that foundation on which such a success may be built. Thus our personality springs from a hereditary soil, but the direction of its growth is more a matter of environment than of germinal determination. Although the Lamarckian hypothesis seems to have no assured place as a real factor in the process of organic evolution, if we widen our conception of this 


\section{BIOLOGY AND SOCIAL PROBLEMS}

process to include the mental growth of man, Lamarckism affords an accurate statement of the way by which much of our mental equipment has come to us, though this statement, as compared with that advanced by Lamarck and his followers, is figurative rather than real. What we do not get by social inheritance, however, we obtain by the strictest kind of organic transmission. Thus our personality is in part an organic and in part a social heritage.

With the evidence so preponderatingly against Lamarckism as an effective factor in organic evolution, there is left as a guiding principle for the transmutationists little more than Darwin's theory of natural selection. This theory is so well known in its general outlines as to require no special exposition. Every species, according to Darwin, produces many more offspring than can possibly reach maturity. These offspring all differ somewhat one from another. In consequence, at any period of stress those individuals whose differences lie in the directions favorable for life are more likely to survive than those that exhibit unfavorable differences. Thus the more favored individuals tend to be preserved and 
to become the progenitors of a new stock bearing the favorable traits.

The individual differences which Darwin believed to afford a basis for this process are not the characters acquired during life, but are those features with which the young organism is born. These differences are germinal in their origin, and therefore may be handed on; in other words, Darwin's theory avoids the difficulty of the inheritance of acquired characters and is based upon what is known to be heritable differences.

That natural selection is a process that occurs in nature seems to be beyond dispute. A single instance may suffice to show this. After a severe winter storm in Providence, Rhode Island, on February 1, 1898, many of the English sparrows of that region were found to be much spent and exhausted. Of these birds, one hundred and thirty-six were collected and brought within doors, and of this number seventy-two revived and sixty-four died. A close comparison of these two sets disclosed the fact that the birds that died were less near the normal than those that survived, showing that, for instance, a heavy body with small wings or a light body with large 
wings was less advantageous under stress of circumstances than a body of average weight carrying wings of average extent. In this instance, then, natural selection could be said to take place in that extreme inclemency tended to eliminate the less fit. Other instances of a like kind have shown that this process is of common occurrence in nature.

But though we may feel confident that natural selection is of actual occurrence, it is by no means certain that it is of first importance. Numerous serious and valid objections to it have been raised from time to time. The most telling of these is the difficulty experienced in understanding how in a given species new characters can get a foothold. The slight individual differences that Darwin assumed to be the beginnings of new traits are altogether too insignificant to be of selectional value, and hence it seems impossible that the initial step in the origin of such a trait could be taken by natural selection. This objection has been fairly met by the mutation theory of De Vries. According to this theory the differences effective in evolution are not the small individual variations, such as were considered so important by Darwin, but the considerable 
sudden changes, or mutations as they have been called, and which, since the revival of Mendel's work, have been found to occur in most animals and plants. These differences, like Minerva, are born in their fullness, and selection may act upon them at once. Thus it is well known that from time to time albino individuals appear in stocks of wild as well as of domesticated animals. Such an appearance is a mutation, and in the case of wild animals living in a district where dark coloration is of protective importance, the individuals bearing this trait would probably be quickly exterminated; but in an environment like the polar regions where whiteness is an advantage, such individuals might well be preserved and in the end give rise to a white stock.

Such hypothetical cases show us how natural selection may take place, and yet we have reason to suspect that the process itself is not so simple. Selection is supposed to act on what Weismann might call the somatic qualities of individuals, coat-color, size of body, strength of muscle, and so forth, and it is assumed that these traits, since they are germinal in origin, would be reproduced in the offspring. But, as we saw from the breeding experiments with 
the black and white guinea-pigs already alluded to, we may have two individuals with indistinguishable exteriors and yet with very different germinal possibilities. One stock of black guinea-pigs, depending upon its ancestry, is able to produce nothing but black descendants, and another stock of black individuals, indistinguishable externally from the first but differing from it in its ancestry, can bring forth white offspring as well as black. In the preservation of black individuals, natural selection would act the same in the two stocks, but one stock would be more effective than the other in establishing a black race. Thus germinal composition may be a factor of no small importance in limiting the effectiveness of natural selection, a process which is of undoubted significance in nature, but which may be much more restricted in its application and effectiveness than its advocates have suspected.

That natural selection influences man as it does other organisms is an undoubted fact. Every epidemic that carries off human beings acts selectively, and if it affects individuals in early life and before the period of reproductive activity, it may have great importance 
from the standpoint of natural selection. Undoubtedly the differences in the immunity to various diseases characteristic of different human races are to be attributed to this kind of influence. But that natural selection has been the main driving force in the evolution of man is no more to be admitted than it is in respect to the other organisms. Natural selection seems to be a real but subordinate factor in organic evolution, the mechanism of which is still to be discovered.

In man much of his social practice tends to reduce rather than to preserve the efficiency of natural selection. In ancient times and in primitive races to-day the malformed or otherwise defective infant is often destroyed, thus anticipating what is likely to happen later through purely natural causes. With the growth in our civilization of the sense of value in human life, these practices have become mostly illegal and have been largely suppressed. As a result we have developed a large body of institutions for the care of our defectives, institutions supported by a strong public opinion. Such social undertakings are in direct opposition to the workings of natural selection. They are a drain on the social body, 


\section{BIOLOGY AND SOCIAL PROBLEMS}

but they are justifiable for the reason that they inculcate a respect for life and a public habit of humane treatment of unfortunates, characteristics without which no race can afford to be. But they are not unqualified blessings. And when we examine them from the standpoint of evolution, they seem to contain an element of no small danger to the state. While it is avowedly advantageous to the community as a whole to treat with all reasonable care its defective members, it is quite clear that this class, so far as its traits are hereditary, is not the class from which the future of society should be recruited. It seems proper, therefore, since our social institutions have counteracted to a certain degree the effects of natural selection and have thus brought about conditions that are unduly burdensome to the commonwealth, if not really menacing to the welfare of society itself, that the state should regulate the reproductive activity of certain classes of defective individuals. This can be done in two ways : first, by educating all persons to a sense of their social responsibilities in reproduction and then relying upon them to act in accordance with this training; and, secondly, where such education is impossible, by sterilizing the 
individual through means that are effective, but that are as little disturbing to his personality as possible. By these methods reasonable self-restraint can be brought into play or a final barrier set in the way of the irresponsible. That so radical a course as the latter is justifiable will be apparent to any one who follows the history of many of the charges in our public institutions for the feebleminded.

In the programme of the eugenicists, I heartily agree with that portion which is directed toward the complete elimination of reproduction by the irresponsible defective. Such a step is merely a reinstitution in modern human evolution of a rapidly disappearing phase of natural selection. When, however, the activity of eugenics is shifted from that of the elimination of the most undesirable to exclusive reproduction by the most desirable, I find it difficult to settle in my own mind how this high-grade stock is to be selected. My neighbors are charitably inclined, but some of them, I am sure, would give what seemed to them good reasons for not having my particular personality repeated in the future, and yet, with all due respect to the welfare of society, 
I confess to a slight measure of feeling that I be allowed some individual freedom in this matter.

And this brings me to another aspect of the social evolution in man. We have seen how immensely powerful and compelling the forces of organic inheritance are, but we have also seen that what we call ourselves is a growth built up in our nervous organization in part directly by daily experience and in part indirectly by what I have called social inheritance. The personality thus developed, though it must depend upon a certain organically inherited soil and cannot rightly flourish unless this is wholesome, is in itself no whit less important a factor in the evolution of man than that of inheritance through the substance of the egg. Memory and above all the ability to act voluntarily are most significant factors in our daily affairs. Without them the fabric of human society would never have come into existence. Voluntary action is a basic fact upon which all social responsibility rests. It makes a code of morals effective. By education this capacity can be greatly improved and set forward and no small part of human progress has depended upon this 
fact. Improvement of this kind through a favorable environment, educational or otherwise, can transform a being whose hereditary outlook is poor into one whose service to society may be great, for a new discovery, a sublime idea, or even a kind act has its place in the evolution of man as much as a hereditary trait. One comes to us by social inheritance, the other by organic. These two processes, the one depending upon the nervous system, the other upon the reproductive mechanism, though treated more or less separately in these lectures, are in reality inextricably interwoven in our natures. For a right understanding and control of our social acts, it is necessary to know the extent to which each factor underlies them. This determined, the organic constituent may be modified, improved, or otherwise controlled through the principles of genetics as applied to the reproductive processes, and the social constituent may similarly be dealt with through environmental changes, training, and education in their broadest sense. These two factors thus mutually interrelated are the fundamental biological elements that underlie our social structure.

In dealing with these elements in the present 


\section{BIOLOGY AND SOCIAL PROBLEMS}

lectures, I have repeatedly taken occasion to point out their relation to the materials of the body. Organic inheritance is dependent upon the minute amount of these materials in the fertilized egg, perhaps even upon those in the chromosomes. By means of these substances and in no other way are the organically heritable traits handed on from parent to child. Social inheritance is dependent upon the approximate cubic inch of nervous protoplasm contained in our cerebral cortex and serving as a means for our conscious operations. When this is removed, diseased, or temporarily disturbed, as by poisons and the like, the whole personality is shaken to the core or even vanishes. From a variety of directions, we have as strong reasons for believing that that whole aggregate of nervous states that we recognize as our inmost selves is as essentially associated with the cortical protoplasm as organic inheritance is with the materials of the egg. In neither case do we understand much of the process. That is a subject for future investigation, but research has gone far enough to show that these two classes of operations, the most wonderful, perhaps, that go on in the body, are bound up indissolubly with their 
several kinds of protoplasm and occur under no other circumstances.

As we know that the materials of the egg cells and of the cortex are undergoing continual disintegration and that the loss that they thus suffer is regularly made good by the appropriation of new material which comes directly or indirectly from the inorganic surroundings, the inference is that our most profound activities are of a purely materialistic nature. And this conclusion seems to me to be entirely correct. But when we think of material, we are prone to regard only its inorganic aspects and we often forget of what it is capable when organized into living substance; in doing this we miss completely its most profound characteristics. In this respect the side of approach is most important. It would be an interesting speculation to inquire what would be our present outlook on nature had science made its first fundamental discoveries in the organic instead of in the inorganic. I am sure that that outlook would have been different from what it is now, but $\mathrm{I}$ am also equally sure that that difference, large as it might seem to some of us at present, would prove in the end to be temporary and illusory, 
for, from whichever side of the problem we make the approach, there is but one goal.

Of the nature of living substance we are only just beginning to get a dim appreciation, but when this appreciation grows to something of an understanding, we shall feel, I believe, no more hesitancy in abandoning our old view of the separateness of self and body and accepting that of their common nature than in the past our race had in giving up Dante's paradise and its ten heavens for the depths of blue above us. Organized living material, as we meet it in the cerebral cortex, is so strictly a part of the universe and yet so strikingly different from any other aggregate of material known to us that we can look upon it at present only with vague bewilderment and yet with a hope, justified by the past progress of science, that in time its secrets will be gradually disclosed to us. With such a view of the potentialities of material, it is not surprising that the biologist finds in the study of organisms a subject of intense interest whose application to the problems of human welfare comes to be day by day more apparent and intimate. 

Che Iriuertion Bregs

CAMBRIDGE - MASSACHUSETTS

U . S . A 





